\title{
Recruitment Strategies, Matrices, and Techniques Used in Hiring Veterans
}

\author{
Dr. Christine Agard
}

Walden University

USA

E-mail: clewin@bestweb.net

Received: January 25, 2017 Accepted: February 28, 2017 Published: April 11, 2017

doi:10.5296/ijhrs.v7i2.10960 URL: http://dx.doi.org/10.5296/ijhrs.v7i2.10960

\begin{abstract}
Successful transition to civilian employment is a challenge for veterans. The purpose of this single case study was to explore critical aspects of hiring managers' decision-making process and to understand how these strategies and techniques affect the hiring of veterans. Tajfel and Turner's social identity theory and Lewin's organizational change model formed the conceptual framework for the study. The participants for this study were 8 hiring managers from a midsized company in the Upper Hudson Valley Region, New York. Data were collected using semi-structured interviews. The data were analyzed and coded and 4 themes emerged: strategies used to fill open positions, specific recruitment and interview protocols, veterans' skills from military training, and lack of experience with hiring veterans. The study results may contribute to veteran's awareness of the skills that employers are seeking that veterans may be able to fulfill. The results of the study could create an opportunity for hiring managers to recognize that veterans represent a trained, ready-made talent pool. The social impact of the study could help hiring managers identify and design the required job description criteria to include the transferable skills of veterans.
\end{abstract}

Keywords: HR and Technology, Interviewing, Gulf War-era II Veterans, Military, Hiring Managers, Hiring Strategies, Recruitment, Organizational Change Theory, Social Identity Theory, Veterans Employment, Leadership 


\section{Introduction}

The U.S. Department of Labor (DoL, 2014), Bureau of Labor Statistics released the population employment status of the civilian for individuals aged 18 years and over, including the veteran status report. In the U.S. Bureau of Labor Statistics report, the unemployment rate for Gulf War-era II veterans was 13.3\% in June 2012, compared with 9\% among civilians in the same age group (DoL, 2014). The difference in the unemployment rates between Gulf War-era II veterans and civilians may be because some civilian hiring managers may not understand the transferability of military skills when juxtaposed with the talent requirements of civilian positions (Benmelech \& Frydman, 2014).

The U.S. military has organized training programs combining service-related educational and on-the-job experience designed to build and develop leadership and management skills (Benmelech \& Frydman, 2014) to help military personnel when they transition out of the military services. Skilled veterans may have difficulties moving from military service to civilian employment because they lack the academic credentials supporting the skills or training acquired in the military (Kleykamp, 2009). The reluctance of hiring managers to hire veterans may place veterans at a disadvantage in the hiring process and may lead to higher unemployment rates among veterans (Benmelech \& Frydman, 2014).

U.S. soldiers are not only infantry soldiers. Over 200 different job skills exist within the military, ranging from logistics, automotive, avionics, medical information, management, and law enforcement (Beauchesne \& O'Hair, 2013). Coupled with the military job skill training are educational and on-the-job experiences, designed to build and develop leadership and management skills (Beauchesne \& O'Hair, 2013). These basic training skillsets can translate into any branch of service and are identical throughout every military branch (Beauchesne \& O'Hair, 2013).

\subsection{Problem Statement}

Hiring managers have the opportunity to find the type of workers they are seeking among unemployed veterans (Beauchesne \& O'Hair, 2013). Without the academic credentials supporting the skills or training acquired in the military, hiring managers tend to overlook veterans between the ages of 25 and 50 as a pool of potential employees (Beauchesne \& O'Hair, 2013). Veteran skill sets mirror the essential functions of positions that business leaders are recruiting (U.S. Department of Veterans Affairs [VA], 2013). The general business problem is that hiring managers are responsible for using fair and transparent hiring processes that identify qualified candidates (Portillo \& Block, 2012); however, these same processes exclude qualified and competent veterans completing their tour of duty. Overlooking this pool of potential employees can place an organization at a competitive disadvantage (Faberman \& Foster, 2013). The specific business problem is there is a lack of relevant strategies, matrices, and techniques that professional hiring managers use to recruit, select, and hire veterans.

\subsection{Purpose Statement}

The purpose of this qualitative single case study was to identify strategies, matrices, and 
techniques that business hiring managers use to recruit, select, and hire veterans. Eight hiring managers from a midsized company in the Upper Hudson Valley Region, New York was the population for this study. Hiring managers were the most appropriate to participate in the open-ended interviews because hiring managers are most suited to identify the strategies, matrices, and techniques used to recruit, select, and hire veterans (Hogan, Chamorro-Premuzic, \& Kaiser, 2013). The goal of the study was to explore strategies and techniques business leaders use to effectively hire veterans. The study results may contribute to sustainable business practices and social outcomes by identifying positions that the veteran population may be able to fulfill and what potential quality of work life nuances may need consideration.

\subsection{Significance of the Study}

The significance of the study was to identify strategies, matrices, and techniques business hiring managers can use to recruit, select, and hire veterans. The study fills a gap in the literature and may enhance knowledge pertaining to the recruitment policies and hiring practices of hiring managers and highlight the business-related skills of the veteran population. Understanding strategies, matrices, and techniques that hiring managers are practicing may contribute to sustainable business practices and social outcomes by identifying positions that the veteran population may be able to fulfill and what potential quality of work life nuances may need consideration. The occupational training individuals receive in the military is similar to several types of civilian employment, yet veterans are having difficulties transferring to the civilian labor market (Beauchesne \& O'Hair, 2013; Kleykamp, 2009; Whyman, Lemmon, \& Teachman, 2011). There are 770,000 unemployed veterans, and more than a million expected to leave the military by 2016 (The White House, Office of the Press Secretary, 2011). Between the challenges of returning to civilian life and the condition of the U.S. economy, new veterans are facing uncertain economic futures. The focus of the study was to gain a clearer understanding of what strategies and techniques hiring managers use to map the experiences of veterans to employment opportunities within their organizations. I explored hiring methods of hiring managers concerning the veteran population to understand if differing strategies and techniques affect job mapping strategies with veterans' KSAs. The knowledge gained from the study could address the recruitment policies and hiring practices of organizations, allowing them to integrate the military culture, language, and skillsets transferable into the civilian workplace, garnering a competitive advantage.

A qualitative single case study exploring the strategies and techniques used by hiring managers, and understanding how these methods affect the hiring practices regarding veterans, provides the opportunity to reduce inequalities in hiring practices and recruitment strategies (Fogle, 2012). Recruitment strategies and hiring practices contribute to the high unemployment rate among skilled veterans moving to civilian employment (Fogle, 2012). The high unemployment rate negatively affects veterans, their families, and the U.S. economy (Faberman \& Foster, 2013). The weak economy is one reason for the high unemployment (Faberman \& Foster, 2013). The unemployment rate for veterans is higher than for nonveterans (Faberman \& Foster, 2013). Though the unemployment rate among 
veterans is decreasing, it remains higher than the national average (DoL, 2014). World War II and Vietnam veterans reentered the workforce during a time of steady employment and a stable economy (Faberman \& Foster, 2013). During the 1980s, a greater number of veterans in the civilian workplace understood military credentialing (Benmelech \& Frydman, 2014). In 2014, with a smaller percentage of veterans in the workplace due to the retirement of workers from the Traditionalist and Baby Boomer generations, newer hiring managers may not understand military credentialing (Benmelech \& Frydman, 2014). Hiring managers need to know and implement strategies and techniques to help with licensing or certification so that veterans can use the skills learned in the military.

\subsection{Definition of Terms}

For the purpose of the study, I include the following definitions for clarification. The listed terms may clarify industry-specific issues yet not be part of common vocabulary.

Baby Boomers: Baby Boomers are those people born in the generation between 1945 and 1964 (Migliaccio, 2013).

Gulf War-era II veterans: Gulf War-era II veterans are men and women who served in the United States Armed Forces anywhere in the world at any time since September 2001 and had returned to civilian life (Walker, 2008). In collaboration with the VA and the DoL's Employment and Training Service, the term Gulf War-era II was developed (DoL, 2014).

Organizational change theory: Organizational change theory is the process of implementing changes within an organization guided by a certain set of rules (Whelan-Berry \& Somerville, 2010).

Posttraumatic stress disorder (PTSD): Posttraumatic stress disorder (PTSD) is a mental illness attributable to a traumatic event such as military combat (Muldoon \& Lowe, 2012).

Reservists: Reservists are guard and reserve personnel that rely primarily on civilian employment with the military providing supplemental income (Griffith, 2010). Reservists devote at least 39 days a year of military service, one weekend a month of drills, 15 days of training, and may be required to serve on active duty (Griffith, 2010). During deployment, reservists can leave their civilian jobs for up to 24 months at a time (LeardMann et al., 2013). Approximately $70 \%$ of the deployed reservists are from small to medium civilian jobs (Griffith, 2010).

Traditionalist: Traditionalist are those people in the generation born between 1925 and 1943 (Gibson et al., 2010).

Veteran: A veteran is a person who served in the armed forces, may have deployed to a war-zone, was honorably discharged, and is eligible for services at the VA (Seal et al., 2008).

\section{Literature Review}

The review of professional and academic literature was essential to create an empirical framework in the research of the high unemployment rate among skilled Gulf War-era II veterans and techniques to map learned military skills with professional job criteria. To 
establish the background for the study, I discussed the concept of Gulf War-era II veterans and military personnel making the transition from the military to a civilian workforce to explain the basis of the research questions. Previous researchers (Beauchesne \& O'Hair, 2013; Faberman \& Foster, 2013) confirmed Gulf War-era II veterans returning to civilian employment had difficulty gaining employment. Faberman and Foster (2013) confirmed that hiring managers, using current processes, place veterans at a disadvantage in the recruiting and hiring process. Beauchesne and O'Hair (2013) confirmed that hiring managers could find the type of workers they are seeking among unemployed veterans. Without the academic credentials supporting the skill or training acquired in the military, hiring managers tend to overlook veterans as a hiring source (Beauchesne \& O'Hair, 2013).

Exploration of the elements of military credentialing and issues and choices for veterans making the change from active duty to civilian life is a function of this study. Organized U.S. military training programs combine educational and on-the-job experience. Designed to build and develop leadership and management skills (Benmelech \& Frydman, 2014), the training programs and the on-the-job experience help military personnel when they transition out of the military services. Whyman et al. (2011) confirmed that military occupational training and experience are similar to college students' or other providers of training. The occupational training skillset is transferable directly to civilian occupations that include technological and managerial skills, which are valuable in the civilian workplace (Kleykamp, 2009).

Within the literature review is a discussion of recruitment and hiring practices and diversity in the workplace. Cole, Rubin, Field, and Giles (2007) conducted quantitative research study that indicated hiring managers should use academic qualification and work experience as the main criteria to determine a potential employee's employability. Cole et al. concluded that hiring managers' judgment about an applicant's work-related skillset might be prone to attribution error. Further, an examination of federal and state law protections for veterans returning to the workforce occurred as part of the review. The implementation of laws and tax incentives pertaining to transitioning to the civilian workforce protects veterans in many ways (Parker, 2012). These laws put amenities into effect to provide veterans with advantages for reemployment, while at the same time giving veterans protection from discrimination (Parker, 2012).

The concept of social identity theory, contributing to a possible disinclination toward hiring veterans, is part of the literature review. Social identity often leads to social competition and even discrimination against groups (Kulik, Roberson, \& Perry, 2007). Social identity theorists help explain prejudice and conflict in hiring decisions (Kulik et al., 2007). Additionally, an exploration of Lewin's concept of organizational change as well as how the absence of organization change theory affects organizations occurs. Organizational change is applicable to the workplace and relate to the concepts of employee recruitment and hiring (Shanley, 2007), which I explored in the study.

\subsection{Gulf War-Era II Veterans Returning to Civilian Employment}

The Department of Defense (DoD) is the largest employer in the United States (Teachman, 2011) with over 1.4 million active soldiers, 26.4 million veterans, and more than 2 million 
retirees (Bailey, 2011; Persyn \& Polson, 2012). Five active-duty branches comprise the DoD and the respective Guard and Reserve units, which are critical to the defense of the United States of America (LeardMann et al., 2013). The branches of the United States military include the Army, Navy, Marines, Coast Guard, and the Air Force (LeardMann et al., 2013). Active duty military personnel primary employment is the military; guard and reserve personnel rely primarily on civilian employment with the military providing supplemental income (Griffith, 2010).

Guard and reserve members, called reservists, make up $46 \%$ of the U.S. Armed Forces (LeardMann et al., 2013). Guard and reserve members of the U.S. Armed Forces support full-time active military personnel (LeardMann et al., 2013). The guard and reserve components of the U.S. Armed Forces include Army Reserve, Navy Reserve, Marine Corps Reserve, Coast Guard Reserve, Air Force Reserve, Army National Guard, and the Air National Guard (LeardMann et al., 2013). Guard and reserve members devote at least 39 days a year of military service, one weekend a month of drills, 15 days of training, and may be required to serve on active duty (Griffith, 2010). During deployment, the guard and reserve members can leave their civilian jobs for up to 24 months at a time (LeardMann et al., 2013). LeardMann et al. (2013) noted approximately $70 \%$ of the deployed guard and reserve members are from small to medium civilian jobs. Uniformed Services Employment and Reemployment Rights Act (USERRA) protects the guard and reserve members called to deployment and provides the returning members' civilian job rights and benefits (DoL, 2014). USERRA provides returning guard and reserve members prompt reemployment back into the same civilian job, with the same seniority, status, pay, and other rights and benefits (DoL, 2014). LeardMann et al. reported that even with the USERRA enactment, returning guard and reserve member reported discrimination and adverse actions resulting from the deployment.

Thousands of Gulf War-era II veterans have returned from wars overseas (Bangerter et al., 2010), and Ra'ees (2010) expected more than a million to leave the military by 2016. Upon return, some veterans' active service military careers will end and civilian life will begin. Some veterans' military careers end by choice and others leave due to combat-related injuries.

The DoL, DoD, and the VA provide services to all military personnel making the transition from the military to a civilian workforce through preseparation counseling and transition assistance workshops (Simpson \& Armstrong, 2009). Some of the transition assistance workshops include employment counseling, employment placement services, resume writing, interview techniques development, education, and training services (Bangerter et al., 2010).

The Gulf War-era II veterans returning to civilian employment have difficulty gaining employment (Kleykamp, 2009). According to the DoL (2014), 33\% of Gulf War-era II veterans have some college but no degree versus 19\% for non-veterans. In June 2011, the unemployment rate for all veterans was $13.3 \%$ compared to nonveterans at $9 \%$ (DoL, 2014). Gulf War-era II veterans between the ages of 20 and 24 had more than double the unemployment rate of nonveterans and almost 3 times higher than the national average (Kleykamp, 2009). 


\section{MInstitute ${ }^{\text {Mink }}$}

International Journal of Human Resource Studies

ISSN 2162-3058

2017, Vol. 7, No. 2

The DoL (2014) reported that about 1 in 4 Gulf War-era II veteran has a service-connected disability diagnoses. Some veterans have obvious disabilities such as blindness, amputations, or mobility impairments. The other not-so-obvious disabilities are PTSD, traumatic brain injury (TBI), or depression (Capehart \& Bass, 2012). Under Title 38, Code of Federal Regulations, Chapter 31, assistance is available for veterans with service-connected disabilities (Gade \& Wilkins, 2013) during and after the transition to civilian life through the VA vocational rehabilitation and employment programs (Sayer et al., 2011). The VA vocational rehabilitation and employment program for veterans provides intensive services to assist veterans to prepare for, find, and keep employment (Gade \& Wilkins, 2013).

Despite protective laws in the USERRA, in a 60 Minutes CBS news report, Stahl (2008) reported thousands of returning veterans have lost their civilian jobs held prior to their deployment, due to demotion, penalization, or firing. The Institute of Medicine (IOM, 2010) committee reported that the reemployment problem, following military service, commonly occurred with veterans formally employed by small businesses. The IOM committee further reported that some small businesses avoid hiring veterans altogether. Griffith (2010) reported extended guard and reserve members' deployment created problems when returning to civilian employment. Military guard and reserve members reported that, after deployment, they returned to lesser jobs and/or were fired when they tried to reestablish a relationship with their former civilian employers (Griffith, 2010).

Perl (2011) examined the needs of veterans with an emphasis on the homelessness among U.S. veterans. According to Perl, the characteristics associated with an increase in the number of homeless veterans were unemployment, having a disability, and being unmarried. Perl provided background information, demographics, programs, and policies on veterans. The reasons for veterans' homelessness vary. Perl reported Gulf War-era II veterans in the homeless program had a higher unemployment rate because they lacked college degrees.

\subsection{Military Credentialing}

The DoD is the largest employer in the United States, including more than 700 different occupations (Benmelech \& Frydman, 2014). Similar to college students or other providers of training, military personnel learn several different occupational training skills (Whyman et al., 2011). The occupational training skillset is transferable directly to civilian occupations, including technological and managerial skills highly valuable in the civilian workplace (Kleykamp, 2009). Following basic training, military personnel training entails specific military occupational specialties ranging from logistics, automotive and avionics, to medical information, management, leadership, law enforcement, and administration. According to Whyman et al. (2011), military occupational specialties provide valuable skills and occupational training used to gain employment after military service in the civilian labor market. Whyman et al. argued that there was an increase in the transferability of the military occupational specialties' training to civilian employment after the postdraft 1973, all-volunteer military force era. Further, Whyman et al. noted that during the draft era there was a $25 \%$ to $30 \%$ transferability rate of skills learned in the military to civilian employment. After the 1973 draft era, the transferability percentage increased to $45 \%$ to $50 \%$ (Whyman et 
al., 2011). As the number of military occupational specialty skills increased, a higher likelihood of veterans finding employment after the military existed (Whyman et al., 2011).

Dawson, Burrell, and Rahim (2010) examined several articles to find out the application of theory in large organizations with specific interest to the DoD. Dawson et al. emphasized on the theory of military organizations and leadership training and transitioning the acquired skills to civilian employment. Furthermore, Dawson et al. revealed how hiring a veteran is an advantage due to the decision-making, theories taught, and the applications to organizations within the DoD. Adler and Castro (2013) further described that military experience provides veterans with valuable skills, experience, and qualifications that include teamwork and leadership, ability to work under pressure and to meet deadline, a high standard of quality, and strong work ethics. Dawson et al. and Adler and Castro highlighted these core principles, decision-making, learning leadership execution through educational means, leadership in the military, and the use in the transition to civilian organizations.

Kleykamp (2010) investigated the military drawdown in the 1990s and its effect on employment rates and college enrollment. During a 5-year period, there were approximately 500,000 military jobs lost because of this drawdown (Kleykamp, 2010). Kleykamp revealed, while the drawdown had little effect on employment rates, the drawdown had a significant impact on college enrollment. Kleykamp noted veterans who left the military because of the drawdown may have gained training and skills, transferable to the civilian sector, and could increase employment rates in general. Bangerter et al. (2010) presented the cognitive information processing theory to help veterans transitioning into the civilian workforce when making new career choices. Bangerter et al. noted the cognitive information processing approach allowed career counselors to address clients' current career problems simultaneously as well as teach veterans skills to make career decisions across their life spans.

Members of The White House Office of the Press Secretary (2011) discussed a plan to assist veterans converting from military service to the civilian workforce. The plan to help veterans transition to the civilian workforce included hiring tax credits, private sector commitments, and government reforms. Christian (2012) discussed work opportunity tax credit (WOTC), which is a federal tax credit incentive enacted by Congress for employers who hire unemployed veterans. In addition to WOTC, Congress enacted the Returning Heroes Tax Credit, and the Wounded Warriors Tax Credit (Parker, 2012). The enactment of these federal tax incentives supports the doctoral study on the problem of unemployment among veterans.

Bullock, Braud, Andrews, and Phillips (2009) surveyed veterans transitioning into civilian employment associative with their interest patterns, barriers to employments, level of negative thinking about a career, and general personality structure to understand career concerns from a veteran's point of view. Bullock et al. revealed that while veterans had a negative career concern comparable to nonveterans, there were more negative factors found associated with veterans' career concerns. Bullock et al. recommended certain opportunities for intervention to aid career counselors when interacting with veterans.

Klusek and Bornstein (2006) examined the job profiles of 21 business and finance 
occupations in the DoL's ONet database to discover if the skills and work activities associated with these jobs demanded an information-literate worker. Klusek and Bornstein found information literacy skills valuable in the workplace and an integral part of the work activities demanded by business and finance occupations.

The implementation of tax incentives provides a synonymous viewpoint that employers will attempt to admit veterans into the workplace as any civilian (Parker, 2012). Information literacy skills hold a valuable perspective while intercessions are in place to guide veterans to handle their apprehensions involving career decision-making (Gati, Ryzhik, \& Vertsberger, 2013). Employers embrace the truth that the military experience portrays veterans as possessing adequate judgments in building honorable firms, during difficult and prime times (Benmelech \& Frydman, 2014). It becomes evident that veterans are profoundly capable of making positive advances in civilian employment (Benmelech \& Frydman, 2014).

\subsection{Recruitment and Hiring Practices}

Hiring well-qualified candidates present human resource challenges for companies (Avery, McKay, \& Wilson 2008). Some employers target certain employees with specific characteristics leading employers to discrimination and prejudice in hiring practices (Portillo $\&$ Block, 2012). Portillo and Block (2012) described discrimination as merely the act of employers engaging in personal tastes and preferences. The legal definition of discrimination is the act of unfair treatment, harassment or, denying rights because of race, religion, gender, age, disability, nationality, sexual orientation, and other defining characteristics (U.S. Equal Employment Opportunity Commission [EEOC], 2012). Antidiscrimination laws are beneficial to employers because by discriminating in the hiring practices, employers face higher costs in several ways (Portillo \& Block, 2012). The example noted by Portillo and Block was the cost in discriminating in the hiring process leads to a smaller pool of job applicants. The smaller pool of job applicants leads to longer and more extensive searches, and the cost includes lost productivity (Portillo \& Block, 2012)

Hays-Thomas, Bowen, and Boudreaux (2012) noted the importance of adopting diversity skills in the workplace. Diversity skills are necessary for success in organizations (Hays-Thomas et al., 2012). Diversity skills help the leaders of organizations attract a diverse and highly skilled set of workers. Veterans' education, training, positions held, and awards earned bring a wealth of diversity of skills to the civilian workforce (Bangerter et al., 2010).

Pager, Bonikowski, and Western (2009) noted workplace discrimination continued to be a subtle yet hard to measure obstacle that limits the minority workforce. To address whether employers' behavior affected employment opportunities for minorities, Pager el al. conducted an experiment on employment discrimination and the effect in the low-wage labor market of New York City. Young qualified men from different races posed as job applicants with similar characteristics. The result of the Pager et al. study revealed that in the direct observation of employer behavior, Blacks were half as likely to receive a callback or job offer as the equally qualified Whites. Despite federal laws prohibiting job discrimination, racial differences in employment remained a cause of economic inequality. 
Perceived workplace discrimination can create a difficult and costly environment for both individuals and employers (Avery et al., 2008). For individuals, perceived workplace discrimination can increase work stress, detract from physical and emotional health, and impact productivity (Avery et al., 2008). For hiring managers, perceived discrimination can undermine employee commitment, lessen organizational citizenship behavior, morale, and can lead to a direct impact on the organization's bottom line (Avery et al., 2008). Avery et al. (2008) examined the affect of demographics on the prevalence of perceived workplace discrimination. Avery et al. surveyed 763 full-time employees throughout the United States. The results of the study reflected that perceived sex-based discrimination at work were more prevalent among female employees than male, and perceived race-based discrimination at work was more prevalent toward Black and Hispanic employees than Whites.

Pearson, Dovidio, and Gaertner (2009) examined how social and historical developments have influenced the intellectual climate surrounding the study of prejudice, and illustrated how the advances in the study reflected one type of racial bias, aversive racism. Aversive racism is a subtly and unconsciously form of bias (Teal, Gill, Green, \& Crandall, 2012). Under the hiring and recruiting context, aversion racism manifests itself when an individual unconsciously or unintentionally discriminates against a job applicant perceived to be different.

\subsection{Employment Laws for Veterans}

Thousands of Gulf War-era II military personnel returned from wars overseas and re-entered civilian employment or searched for new employment (Greenwald, 2012). Several federal and state laws provide protection for veterans from employment discrimination, starting with the Veterans' Preference Act, enacted in 1944. The Veterans' Preference Act granted veterans preference over non-veterans in hiring practices wherever federal funds are utilized (Greenwald, 2012). The Vietnam Era Veterans Readjustment Act of 1972 is a similar act because private employers, contractors, and subcontractors required by law to give disabled or Vietnam veterans' preference in hiring when working on federal contracts (Greenwald, 2012).

The Civil Rights Act of 1964 prohibits discrimination on sex, race, hiring, firing, and promoting (Maldonado, 2011). Title VII of the Civil Rights Act specifically focused on discrimination in employment in any business with more than 25 employees (Maldonado, 2011). Title VII applies to the hiring, promotion, firing, promotion, demotion, compensation, fringe benefits, job training, and all other aspects of employment (Hagen, 2011). Title VII of the Civil Rights Act is important because this act provides equal employment opportunity for everyone based on the individual's abilities necessary to perform the job.

Enacted in 1990, The Americans with Disabilities Act (ADA) protects individuals with disabilities from discrimination, unemployment, and allows access to various social institutions (O'Brien \& Brown, 2009). The ADA's criteria to determine if an individual is disabled are: (a) an individual that has a physical or mental impairment substantially limiting that individual's life activities; (b) an individual that has a history of such impairment; or (c) an individual perceived to have such impairment (Clarke \& Cohen, 2010). Title I of the ADA 
covers all aspects of employment and prohibits employers with 15 or more employees from discriminating against an individual who, with reasonable accommodations can perform the essential functions of the job (Bowman, 2011). For example, it is illegal for employers to discriminate against a veteran that has PTSD or assumes that the veteran has PTSD (van Bogaert, 2008). The ADA further prohibits employers from obtaining or conducting veterans' pre-employment medical information unless the inquiries are job-related and justified (van Bogaert, 2008).

Enacted in 1994, USERRA protects service members in four different ways: (a) reemployment after service, (b) reemployment to the civilian position the service member held prior to active duty deployment or a similar position, (c) prevent employers from discriminating against service members because of service, and (d) prevents employers from dismissing service members without just cause within 180 days to one-year (Pate, 2011). USERRA discrimination protection applies to all employers regardless of size and extends to all employees, including managerial and professional employees (Ogles, 2012). Additionally, there are federal laws making the recruiting and hiring of veterans a priority. Even with these laws, some hiring managers are still reluctant to hire veterans (Parker, 2012). The U.S. government has enacted the Veteran's Opportunity to Work (VOW) and Hire Heroes Act of 2011, to encourage employers to hire veterans with service related disabilities, by providing tax credits and incentives for employers (Parker, 2012). The tax credit provides incentives up to $\$ 9,600$ for hiring unemployed veterans with service related disabilities (Parker, 2012).

The implementation of laws and tax incentives, pertaining to transitioning to the civilian workforce protects veterans in many ways (Parker, 2012). These laws put amenities into effect to provide veterans with advantages for reemployment, while at the same time giving them protection from discrimination. USERRA assures the protection of our heroes. As of 2011, several tax enticement programs such as the VOW program encouraged employers to hire our veterans, despite handicaps and disabilities. It is in our nation's future to mainstream veterans into the civilian lifestyle of today's workforce (Tucker, Sinclair \& Thomas, 2005).

\subsection{Social Identity Theory}

Human resource managers display stereotypes with respect to an applicant's social categories, such as age, race, disability, or gender (Kulik et al., 2007). Kulik et al. (2007) suggested that when matching an applicant to a job, human resource managers possess an awareness of the applicant's social identity. These stereotypes can influence the human resource manager's hiring decision without the person's knowledge (Kulik et al., 2007).

Social identity theory, that was built on Festinger's (1954) social comparison theory, attempts to explain how groups of people categorize themselves leading to behaviors and in-groups within organizations as cited in (Cannella, Jones, \& Withers, 2015). Tajfel and Turner developed their social identity theory in 1979 (O'Fallon \& Butterfield, 2012). Tajfel and Turner (1986) defined social identity theory as the connection of a group membership and the value significance placed on those group memberships (Pearce, 2013). Early motives for social identity theory were to enhance self-esteem within the in-group to promote distinctiveness (Deaux \& Burke, 2010). Later, researchers posited several other motives 
including uncertainty reduction about one's place within the social world, and maintaining balance and consistency (Deaux \& Burke, 2010). For both the individual who adheres to a specific social identity and those who view them as belonging to a particular category, social identity has many implications beyond labeling (Major, 2012). The category label may be the fabric containing a rich tapestry of cognitive beliefs, emotional associations, and behavioral consequences (Major, 2012).

Due to the social capacity of individuals, people have expectations about specific stereotypes (Deaux \& Burke, 2010); the expectation that one is judged because of their social group membership and not because of actual performance or potential may be a roadblock to employment (Block, Koch, Liberman, Merriweather, \& Roberson, 2011). Social identity expectation transfers during social interactions with other persons, as well as, society (Block et al., 2011). Social identity expected standards help train individual behavior and targets self-definition within the organization (Deaux \& Burke, 2010).

Social identity theorists focus on conditions that lead members of an individual group, known as the in-group, to discriminate against others, known as the out-group (Tajfel \& Turner, 1986). Tajfel and Turner proposed that social identity theory centers on three mental processes: (a) social categorization, (b) social identification, and (c) social comparison. The first stage, social categorization is the process of categorizing people in the in-group or the out-group (Tajfel \& Turner, 1986). The second stage, social identification is the process wherein the group members share a common identity and conform to the norms of the group (Tajfel \& Turner, 1986). When individuals attach a huge sense of identity to their group membership, an endangered identity develops and a conflict exists between the in-group and the out-group; and prejudice or negative feelings are more likely to occur (Bilewicz \& Kofta, 2011). The final stage, social comparison, is the process an individual categorizes himself or herself as belonging to a specific group as compared to other groups (Tajfel \& Turner, 1986).

Under social identity, grouping of individuals may occur based on race, nationality, gender, ethnicity, religion, age, or a variety of other factors (Ashcraft, 2013). Identity also can be associated with the profession (Gade \& Wilkins, 2013). Professional identity formed as individuals adopt behaviors and preferences in-sync with the goals of the organization, thereby changing the impact his or her own values may have on the behavior of the bureaucracy (Gade \& Wilkins, 2013). Gade and Wilkins defined veterans' identities as a unique and separate class within society. Veteran's status has become a group-based social identity, more than an individually based identity (Brewer, 2001). Brewer explained the process as the fortunes and misfortunes of how the group form and become responsive to personal outcomes, forming a protective group for veterans. For example, Gade and Wilkins noted that veterans identify themselves by war era, location, and length of service, combat exposure, service-connected disability, and rank.

Empirical research literature refuting social identity theory is sparse. Most of the studies on social identity focus on collective identities (Ashforth, Harrison, \& Corley, 2008). The importance of social identity theory to the current study is that it introduced the concept of categorizing salience hierarchy. Considered a collective whole, veterans identify easily with 
their peers (Brown \& Gross, 2011). When working with a veteran, other non-veteran employees may find it difficult to relate to typical work situations due to their social identity (Brown \& Gross, 2011). Having effective veterans' support groups can help ease the veteran into the workforce with little to no stress (Brown \& Gross, 2011). In contrast, the shared view of stress implies that climates permeate entire workplaces and may even affect employees who do not personally feel excessive role demands (Brown \& Gross, 2011). Social psychological research on social identity formation pinpoint psychological processes to expound on how these effects might occur (Brown \& Gross, 2011).

While discrimination laws were enacted to create equality and diversity in the workplace (Jones \& Lewis, 2011; Portillo \& Block, 2012), according to Kulik et al. (2007), human resource managers use social identity stereotypes when making hiring and promoting decisions that can lead to discrimination and biases in organizations. The effects of social identity not only have a role in the applicant obtaining an interview, but can also influence the overall evaluation of the interview (Dovidio, Gaertner, Kawakami, \& Hodson, 2002).

Individuals have several career choices besides the military (Deaux \& Burke, 2010). To maintain the required level of staffing within the military, Congress enacted various benefit packages to attract new recruits (Deaux \& Burke, 2010). The military leaders place significant emphasis on education and training offered to veterans as a means of integrating returning veterans into the civilian workplace (Deaux \& Burke, 2010). The utilization of social identity theory in the study illustrate how hiring managers can use the construct of social identity theory to assist them in the hiring and recruiting of veterans to eliminate the barriers in veterans' employability and to develop diversity in the workplace (Herring, 2009).

\subsection{Organizational Change Theory}

The concept of organizational change is a common theme in most organizations regardless of industry or size (Reddin \& Stuart-Kotze, 1972). Organizational change must occur in order to realize possible benefits and transition from compliance to a responsible organization (Teelken \& Watson, 2014). A variety of the organizational change theories exist in the literature review. Some are Lewin's (1951) three-stage organizational change, Reddin and Stuart-Kotze's (1972) change theory, and Kotter's (1996) field of change management.

Lewin (1951) played a key role in the evolution of organizational development that includes human resources development and communication. Lewin identified three stages of organizational change: (a) unfreezing technique reduces residence to change; (b) movement technique involves developing new behavior and attitude through training; and (c) refreezing or freezing technique return the organization to a new state of stability. The ongoing work team guided by the change agent or catalyst directs the identified steps of change (Lewin, 1951). The ongoing work team and the change agent show commitment to organizational development at all stages of the activities, including the diagnosis, implementation, and evaluation (Bell \& Bodie, 2012). The commitment to organizational development at all stages is important to a successful change (Lewin, 1951). While an organization may have individuals in leadership positions, not all of those individuals may possess leadership qualities (Bell \& Bodie, 2012). As Bell and Bodie noted, there is an identified need for 
developing leaders who can implement organizational change. Furthermore, Bell and Bodie stated that the change agent or catalyst looked for effective change or multivariate theories to explain the course and outcomes of change that guide the theory of change management. According to Benmelech and Frydman (2014), there is a lack of corporate organizational leaders with military experience. Leadership knowledge, training, and experiences are the main characteristics of the military, which are valued in a competitive business environment (Benmelech \& Frydman, 2014). Drawing from Lewin's organizational change theory in the study provides a perspective on how the absence of organizational change theory affects organizations. In the undertaking of any substantial organizational change, hiring managers would be wise to examine the availability of the right individual to lead the change.

Kotter (1996) defined the field of change management as the process of implementing changes within an organization guided by a certain set of rules. Examples of change management include culture changes, vision and mission changes, operational changes, and strategic changes. Kotter introduced eight steps for successful change management: (a) understanding the implication such a change will have on the employees, (b) developing an effective team that understands the organizational values and culture, (c) change management team should work to ensure buy-in from management and stakeholders, (d) develop effective communication methods, (e) effective training or skill upgrading, (f) plan for employee resistance, (g) celebrate important milestones and achievements, and (h) solicit feedback and input which will further improve change management approaches for the future. Kotter indicated that change is constant and difficult to predict. Organization leaders must expect the unexpected and design processes and controls that minimize the disruptive effects of unexpected changes (Kotter, 1996). Further, Reddin and Stuart-Kotze (1972) developed a theory of change that can be used by organizational leaders. Reddin and Stuart-Kotze indicated that organizational leaders should assess their business environment, identify the most appropriate behavior, and implement change effectively. Reddin and Stuart-Kotze suggested seven techniques used to implement change. Diagnose, mutual setting of objectives, group emphasis, maximum information, discussion of implementation, use of ceremony and ritual, and resistance interpretation. The first technique emphasized by Reddin and Stuart-Kotze is that organizational leaders may observe the environment and diagnose the problem. Second, ensure that all employees whom the change will affect are aware of the goals of the change. Third, emphasis that affected group or team will help to execute the change. Fourth, provide information to group or team members affected by the proposed changed. Fifth, create and discuss with the group or team members the plan for implementing the proposed change. Sixth, study the culture in the environment and apply any existing ceremonies in the environment to keep the employees involved in the change process. Seventh, after the implementation of change, organizational leaders may check for any resistance to change. By using Reddin and Stuart-Kotze's theory of change techniques, organizational leaders could present a positive image of the industry to attract, recruit, and retain skilled workers.

Hiring managers might be able to apply Lewin's (1951), Kotter's (1996), or Reddin and Stuart-Kotze's (1972) change theory model as a framework for their organizational change. 


\section{$\triangle$ Macrothink}

The multiple model approach requires organization leaders to increase competitiveness by improving their organizational effectiveness and flexibility (Shirey, 2011). Lewin emphasized human resources development and communication, Kotter focused on all aspects for the change to happen in an organization, and Reddin and Stuart-Kotze focused on the collaborative relationship between all employees to overcome resistance to change management.

According to Maon, Lindgreen, and Swaen (2009), Lewin's (1951) change theory is the most popular because it revolves around the concept of doing away with previous processes to allow new processes to become the norm. As business processes and practices become outdated and are no longer suitable for the competitive situations, organizations move toward changes (Hanafizadeh \& Osouli, 2011). Hanafizadeh and Osouli (2011) suggested all corporations radically reinvent how their business processes work, and could try to achieve radical performance gains. The changes do not necessarily need to be drastic changes. Minor changes in the processes, team, or system incorporated for growth of the organization affects the whole organization or industry (Hanafizadeh \& Osouli, 2011). In contrast, some changes are routine and others non-routine (Hanafizadeh \& Osouli, 2011). The change can be structural change, cost change, process change, or cultural change (Hanafizadeh \& Osouli, 2011). Alteration to the organizational structure or reorganization due to a merger and acquisition come under structural changes (Stare, 2010). Attempts of an organization to reduce the costs incurred on various processes (Stare, 2010). The processes include departmental cost cutting, reducing budgets, laying-off employees, and removing non-essential activities along with the improvement in efficiency or performances are cost changes (Stare, 2010). Process changes are the implementation of new processes in manufacturing, the service industry, or by modifying the current process to improve efficiency or effectiveness of organizational procedures (Stare, 2010). Cultural changes are the least substantial of all the types of change but can be the most difficult (Stare, 2010). An organization's culture consists of shared assumptions, values, and beliefs. When organizational leaders attempt to adapt to various changes in the culture, they face problems aligning the organization's culture to the diverse individual (Northouse, 2010). Organizational leaders implement certain techniques and testing necessary for organizations to be sustainable.

Christensen, Marx, and Stevenson (2006) highlighted the need for leaders to instill cooperation to elicit change in an organization. Christensen et al. conducted an analysis of types of leadership and the effectiveness of those styles in fostering change. Leaders are typically relying on one style predominantly and not being flexible to understand the leadership style needed to foster collaboration in a given situation for based on need (Christensen et al., 2006).

Leigh, Shapiro, and Penney (2010) conducted a mixed-method research study that examined the effectiveness of the leadership development methods undertaken by the Emerging Leaders Program (ELP), from corporate and non-profit sectors in the Boston area. Leigh et al. focused on leadership training programs and the ability to instill leadership traits that foster collaboration within an organization and work groups. Leigh et al. attempted to bridge the 
gap between traditional leadership styles and a more recent finding that collaborative leadership is necessary and more effective in affecting change.

Shanley (2007) conducted research on the disparity between a middle managers' experience with management of change and the ability to lead change efforts, and the support needed to develop their skills organically. Shanley found that managers do not have a clear understanding of how to integrate management of change within their day-to-day job duties. Shanley concluded although managers are skilled as leaders, being effective in managing change often requires skills, which may not be inherent, but rather developed. In contrast, Chamberlin (2010) examined how leaders are not always those in charge, but those that have influence. Chamberlin suggested that leaders are those whom others go to for answers. Chamberlin explained how to identify leaders who already exist, and recruit professionals who would provide a model for leadership. Furthermore, Chamberlin's study shared the cycle of leadership - delegation, decision-making, and accountability.

Cowan Sahadath (2011) studied organizational change process by focusing on whether senior management verbal interactions influence organizational behavior. Furthermore, Cowan Sahadath illustrated the importance of spoken conversations with subordinates. Several implications emerged from the research; Cowan Sahadath stated that the result of the study helped senior management gain a clearer understanding of how effectively verbal interactions with subordinates influenced business change. Cowan Sahadath explained the urgency of developing change leaders that are aware of the importance such conversations play in leadership.

According to Hays-Thomas et al. (2012), diversity organizational change arises from the top management learning new things and unlearning others can lead to changing oneself. Organizational change stems from the conversion of individual learning to collective learning (Van de Ven \& Sun, 2011). Organizational change is an ongoing and never-ending process of organizational life (Van de Ven \& Sun, 2011). Breakdowns occur when organizations do not change inconsistencies within the change process (Van de Ven \& Sun, 2011). Change is complex; once a breakdown is identified the proper change model must begin (Van de Ven \& Sun, 2011). Embedding change process in an organizational system is critical (Van de Ven \& Sun, 2011).

One can observe how organizational structure plays a role in the outlook of veterans in the civilian workplace. The employers setup a system of structural change that integrates process, as well as cultural change (Cullen, Edwards, Casper, \& Gue, 2014). Employers strive to input modifications when utilizing change (Hanafizadeh \& Osouli, 2011). The use of leadership is to incorporate the needs of the organization cohesiveness and the workgroup (Sloan, 2013). The study continues to ascertain the impact on experiences during the hiring process (Demuijnck, 2009).

\section{Research Question}

The central research question for the study was as follows: What strategies, matrices, and techniques do hiring managers use to recruit, select, and hire veterans? 


\subsection{Interview Questions}

1. What are the critical requirements and how does your organization identify and evaluate these requirements when making a new hire decision?

2. How do you map hiring criteria and the knowledge, skills, and abilities (KSAs) when comparing military learned skillsets?

3. How might the KSAs of a veteran strengthen your organization for a qualifying position?

4. What is your process for evaluating job skills needed to drive change within your organization?

5. What strategies, tools, and techniques, if any, do you use to determine job competencies of veterans and nonveterans for equivalent positions?

6. How do you determine the criteria in the job description accurately reflect the transferable skills developed by veterans?

7. What strategies and techniques have you used to bridge the employability gap(s) regarding veterans?

8. What additional information you believe will add value to the study?

\section{Methodology}

A qualitative method was appropriate for this study because of the nature of the problem statement and the requirement to analyze intangible elements such as an individual's attitudes, experiences, beliefs, and behaviors. Qualitative research enables researchers to understand the complexity of social phenomena through semistructured and open-ended interviews designed to seek answers to questions on the creation and sustainability of social actions and social experiences (Damico \& Ball, 2010). Quantitative or a mixed method was not appropriate for the study because quantitative research does not depict the human experience (Gelo et al., 2012). Using a qualitative method to explore the hiring techniques and strategies of organizational leaders and understand how these methods affect the hiring practices regarding veterans was deemed the best choice for this study.

I selected qualitative case study design approach to obtain information on the hiring practices of an organization collected from individuals who can demonstrate the phenomenon under investigation. Experiential knowledge rather than abstract and theoretical knowledge is the emphasis on a case study design (Yin, 2011). Case studies are ideal in complex situations wherein the researcher tries to understand and improve a business practice (Yin, 2011). Case study design describes commonality among the participants (Yin, 2011), and in the current study, hiring practices, strategies, and techniques used defined the commonality.

\subsection{Population and Sampling}

The population for the study was eight hiring managers with one or more years of hiring experience from a midsized company in the Upper Hudson Valley Region of New York. As 
posited by Chenail (2010), I used purposive sampling and a subcategory of purposive sampling called snowball sampling in the selection of the participants that will best match the desired characteristics of the population. Using a purposive sampling technique allows for the selections of participants who can assist in recognizing the problem and the research question and using the snowballing technique allows data saturation to occur (Suri, 2011). To ensure the collection of sufficient data, I interviewed a sample size of six hiring managers within the research company initially; however, the data collection process continued beyond this initial number to eight hiring managers when no new data emerged and data saturation was achieved. Furthermore, the review of secondary materials such as, organizational documents, websites, archival reports, and brochures related to the study to triangulate data and ensure data saturation.

\subsection{Data Collection}

I conducted in-depth qualitative open-ended interviews as the data collection method for the study. Open-ended interviews will allow each participant, who has experienced the phenomenon of recruiting veterans, to articulate his or her lived experiences effectively (Onwuegbuzie et al., 2012). Open-ended question interview process will include questions that will provide the opportunity to explore any impromptu issues relating to the problem statement based on the participants' responses (Gelo et al., 2012). I conducted the interview process face-to-face except in one case in which the participant was not accessible. I utilized telephone interviews at the participants' request and convenience.

\section{Results}

I conducted methodological triangulation by utilizing the interview responses, member checking, company documentation, and academic review of the literature that correlated with data obtained from the interviews. The first level of identification occurred during the initial review of each interview transcript. I read each transcript, analyzed each interview response, and then conducted open coding utilizing NVivo software, analytic tool used to facilitate the coding process. I have summarized the four primary themes related to this research question in this section. In addition, I have further classified three of the primary themes into subthemes. Table 1 shows the frequency with which the themes appeared throughout the interviews and across the data.

Table 1

Frequency of Themes for the Central Research Question 


\begin{tabular}{|c|c|c|}
\hline Theme/Subtheme & $\begin{array}{l}\text { Number of } \\
\text { interviewees } \\
\text { mentioning this theme }\end{array}$ & Total quotes \\
\hline \multicolumn{3}{|l|}{ Strategies used to fill open positions } \\
\hline $\begin{array}{l}\text { Hiring managers ensure potential hires have } \\
\text { relevant experience }\end{array}$ & 7 & 16 \\
\hline $\begin{array}{l}\text { Hiring managers list the required skills in a } \\
\text { job description }\end{array}$ & 5 & 6 \\
\hline Hiring managers use lists of competencies & 1 & 2 \\
\hline $\begin{array}{l}\text { Hiring managers verify certifications or } \\
\text { licenses }\end{array}$ & 3 & 5 \\
\hline $\begin{array}{l}\text { Hiring managers evaluate employees in the } \\
\text { same manner }\end{array}$ & 2 & 2 \\
\hline \multicolumn{3}{|l|}{ Specific recruitment and interview protocols } \\
\hline $\begin{array}{l}\text { Hiring managers do not do anything } \\
\text { differently for veterans }\end{array}$ & 6 & 8 \\
\hline \multicolumn{3}{|l|}{ Veterans have skills from military training } \\
\hline Veterans are disciplined and responsible & 6 & 8 \\
\hline Veterans have leadership skills & 5 & 6 \\
\hline Veterans can work with a team & 4 & 5 \\
\hline No experience with hiring veterans & 2 & 3 \\
\hline
\end{tabular}

Note. Subthemes are italicized.

\section{Theme A: Strategies Used to Fill Open Positions}


The most frequent reoccurring theme included the specific strategies hiring managers used to hire employees for organizational fit. Within this theme, the participants identified the key factors they used to recruit, select, and hire employees. Based on the eight participants' responses and the review of the organizational documents, the strategy for hiring managers includes the review of resumes of potential candidates and the use of a hiring matrix (Tsai, Chi, Huang, \& Hsu, 2011). The review of resumes and hiring matrices theme supports the academic literature and the social identity theory. When matching an applicant to a job, hiring managers possess an awareness of the applicant's social identity (Gholston, 2015). This was a clear theme that emerged from the participants' responses. Hiring managers are the gatekeepers to the workplace (Malos, 2015); therefore, their hiring and recruiting strategies are of importance to the workforce. Although the hiring managers' main focus is on recruiting and hiring decisions aimed at attracting the right candidates, there is reason to believe that hiring managers' personal feelings and biases can play a crucial role in these decisions (Ruggs, Hebl, Walker, \& Fa-Kaji, 2014). This appears to lead to unrecognized discrimination.

As a result of the data analysis, five subthemes emerged with regard to hiring strategies used by hiring managers: (a) hiring managers ensure potential hires have relevant experience, (b) hiring managers list the required skills in a job description, (c) hiring managers use lists of competencies, (d) hiring managers verify certifications or licenses, and (e) hiring managers evaluate all employees the same manner.

Subtheme 1: Hiring managers ensure potential hires have relevant experience. Participants mentioned this 16 times in seven interviews. For example, P1 stated, "Then we also like to see some experience." Later this same participant elaborated and explained,

I don't know that I look necessarily whether it's veteran skills and... Skills, what did you say? Abilities and knowledge or a layman, as long they have it, again I don't care exactly where it occurs. Now because what I really look for is experience providing personal care assistance, showers, medication administration or assistance rather. Experience working with dementia, things like that. I don't know how much opportunity there is within the military structure for that. But as long as it's there, again, it doesn't matter whether it's a military setting that it happened in or a civilian setting.

P2 said, "When making the decision to hire or not to hire an applicant, the most critical elements are their experience and qualifications." P3 indicated that "experience, sincerity, compassion, patience, and understanding" were important when hiring for a position.

When asked, "For instance, if you come across a vet. For instance, if you post your positions and you get an application and it's a vet. How do you map what you're looking for to what the vet might have learned in the military?" P4 said,

Probably just, look for what kind of things and experiences people have had that could add to it. Someone that has a lot of variety or a lot of education, or work experience really stands out. Because we want people who can pick up things fast, be a quick learner. We're willing to train, but obviously if we have someone that applies with no experience versus someone that has experience, that would kind of be higher on the list of consideration. 
In a final example of this theme, P7 stated,

We look at any background in sales and marketing. Backgrounds in the hospitality industry are very compatible for this industry, in the sales office, so that helps. Again, having a good personality, someone who can really do discovery, have conversations with people to get to understand them and know what it is that they're looking for, 'cause it's a big process. So it would have to be personality, communication, sales background, hospitality background, any kind of customer service background. Those are all things that we look for.

Seven participants posited that relevant job experience and academic qualifications are extremely important in the hiring and recruiting process. For example, candidates lacking a college degree are not included in the hiring selection that requires candidates to have a college degree in order to qualify for an open position. In this theme, the participants appeared to support this stereotyping process as being justified discrimination based on educational level. This stereotyping process leads hiring managers to make assessments about a candidate's ability to perform the job adequately. These job suitability ratings influence hiring decisions (Heilman, 1983). My immediate thoughts on hearing this theme were that this is no direct relationship between behavioral competencies required in a role clearly linked to a specific educational level.

Subtheme 2: Hiring managers list the required skills in a job description. Participants mentioned this subtheme six times in five interviews. P3 shared, "All applications list what we're looking for in the job description and the HR department will take information from the job description to advertise what they're looking for." P4 said, "The job descriptions are pretty basic for the position." P5 explained what the job descriptions include:

The job descriptions were all developed prior to me coming on board. I came to a lot. I was the lowest man on the totem pole. It was an entry-level position. As I grew up to management, we did make changes to job descriptions and requirements just due to the fact that the facility needs not so much to specifically hire certain individuals. Over the years, we've done more in-house work, and compared with other buildings in the region, we've adapted new requirements for every level to be able to do more in-house work.

When asked, "How do you determine the criteria in your job description to accurately reflect the transferable skills developed by veterans?" P7 noted the following about job descriptions:

Well, I answered an ad I found on Indeed to get this job. There was nothing in there that said they're looking for veterans, but what was in there was leadership, dependability, all of those things, and I think that those are the skills that you would find in a veteran. So I think that, that would probably be the best connection that we would...

In another example of this theme, P8 said, "Well, obviously we have job descriptions for all the different roles that we have." Later in the interview P2 also shared, "We do have job competencies listed in all our job descriptions, so I think that's something that we look at very seriously."

Six participants confirmed the use of job descriptions as a foundation when developing job 
openings in their organization. Participants confirmed that factors such as knowledge, skills, and abilities of a candidate influence their hiring decisions. Candidates with specific skillset help organization complete work tasks and provide competitive advantage (Mwangi, Olay, \& Simuyu, 2015). The participants corroborated that veteran received a wealth of knowledge, skills, and competencies through practical military experience transferable to civilian employment. I was surprised to learn that their job description did not include military culture and experience that could increase recruitment and hiring of veterans.

Subtheme 3: Hiring managers use lists of competencies. Participants mentioned this theme two times in the interview with P8. P8 explained,

So, we do use job competencies. For instance, some are specific; in maintenance, "Do you know how to use a lawn mower? Do you know how to use a weed whacker? Do you know how to use a circular saw?" Those kinds of things. And some are more specific, "Tell me about your supervisory skills. Tell me about..." So, I think with the military-learned skill sets, it would depend... There are the skill sets of very specific task-oriented competencies and then there is the skill set of things that they may have learned in the military that would give them leadership, supervisory skills, etcetera. So, we do use those competencies as kind of a road map when we're doing hiring.

I mean, like I said we do have competencies, so it might be things like... Even things like, "How do you respond to being given direction?" And that might be something from the military. Well, obviously someone from the military is gonna respond well to get... Or they wouldn't have survived in the military. So, that is, "How do you follow commands, directions, orders?" Those kinds of things that might translate a bit.

Within this subtheme, the participants confirmed the use of a list of required competencies, along with resumes, in terms of finding the best candidate for a position. Tas and Ergin (2012) stated that using different methods to find the right candidate, lower organizational cost while ensuring a quality hiring practice. As mentioned earlier, hiring managers perceive veterans as having received a wealth of knowledge, skills, and competencies through practical military experience. This suggests that the problem lies not in the actual skills obtained by the veteran, but in the translation of the military experience and describing those experiences into private sector jobs.

Subtheme 4: Hiring managers verify certifications or licenses. Participants mentioned this theme five times in three interviews. P1 indicated that a PCA was a critical requirement that all candidates, irrespective of their military status, must have,

The critical requirement for our direct care staff is a Personal Care Certificate. It is a New York State certificate that's verified by HR through some sort of certification system. They look it up through the state...I don't care where the experience happens as long as some experience happens. As far as I know, Department of Health does not have a military equivalent for the personal care certificate. And because that's written into my state regulations, whether you're military or non-military, you would need to have that certificate. Again, that's because I need to have that PCA certificate. The more experience they have, the 
better. But it's all a moot point without that certificate.

P4 indicated that a license was needed, "Depending on the department. Obviously, for like nursing, we look to see that they have licenses or they're certified." P8 also mentioned the role of certifications and licenses,

So, I think there are different requirements depending, obviously, on the position we're hiring for. Because, some positions will require certifications, licensure, etcetera, whereas some others don't. An example being, a housekeeper doesn't need a particular certification or license, but an LPN or RN obviously has to. So, I think that's key.

This subtheme raises again the issue of possible misunderstanding between the military skillset and civilian role. As participants suggested, veterans have a variety of military skillsets such as leadership, flexibility, discipline, teamwork, and specialized advanced training in engineering, administrative, medical, and computing. The training for these military skillsets is arduous, and not easily completed in a short period. Hiring managers can tap into a readymade talent pool that possesses a number of required credentials. This can only occur if both parties are speaking from a vocabulary that both parties understand, even when the actual descriptions discussed may be different.

Subtheme 5: Hiring managers evaluate employees the same. This subtheme refers to hiring managers evaluating employees the same, irrespective of their military status. Participants mentioned this theme two times in two interviews. When asked about evaluating employee, P3 explained,

There is an annual job evaluation that employees undergo every year. It's a standard form that we as department heads have to review the year and evaluate the employees' performance on the job, and provide goals for them to achieve in the upcoming year. And provide opportunity for the employee to give feedback to us as well, not only verbally, but there's a section on the evaluation form where they can write comments that they'd like to, suggestions, anything going forward, that can help improve any processes here in the organization. There is a performance improvement process and committee that meets monthly to address any concerns that we can work on with the employees, including all the employees in various projects to help with performance improvement.

In the second and final example of this theme, P6 stated, "We use all the same for anybody. I don't separate the veterans and the non-veterans. All the evaluation tools are the same."

The participants' responses on this theme surprised the researcher, responses that indicated a possible lack of knowledge of or misunderstanding of the rights of veterans. Veterans are a protected status under several circumstances (Greenwald, 2012). For example, the ADA protects veterans with non-apparent or visible disabilities from discrimination, unemployment, and allow access to various reasonable job accommodations (O'Brien \& Brown, 2009). What the participants presented as a virtuous confirmation of a lack of bias, can easily be understood as discrimination through ignorance of the relevant statutes.

\section{Theme B: Use of Specific Recruitment and Interview Protocols}




\section{MInstitute ${ }^{\text {Macrothink }}$}

International Journal of Human Resource Studies

ISSN 2162-3058

2017, Vol. 7, No. 2

The second theme, hiring managers follow specific recruitment and interview protocol, participants listed additional strategies used to hire employees for organization fit. The first interview question was, what are the critical requirements and how does your organization identify and evaluate these requirements when making a new hire decision? The participants' responses and company hiring documents supported the academic literature and related to both conceptual framework theories. The theories include social identity theory and organizational change theory. Social identity theory focuses on strategies for hiring the best candidate despite social affiliation (Bergerson \& Huftalin, 2011). Effective hiring practice can recruit and hired competent workforce, increase employee attitudes, and work performance to develop organizational change (Sloan, 2013). P2 indicated, "Our HR coordinator and I will conduct the interviews, separately or together, then compare our notes and observations. While the decision to hire is mine, I do ask for feedback to help make the best decision." P3 described the interview process,

Some of the ways that we identify them is background check, references, both professional and personal references, and then the interview process. They are interviewed initially. Once applications/resumes are received, they're reviewed by the HR department, and then the HR department determines which ones they would want to bring in for an interview. They meet with the candidate and then they contact the department head of the job they're applying for. Whether it's in the dining service or nursing, they'll contact the department head who'll then follow up with another interview. The HR representative felt that it was a good candidate worth pursuing another interview.

P5 mentioned,

So, actually the only interview that I conduct with them is essentially a one on one, I will get a copy of their job description, review their current work history, ask several questions just to try to get a feel for their work abilities and what they've done, what they feel they can do.

When asked, "How do you determine the criteria in your job description to accurately reflect the transferable skills developed by veterans?" P6 said,

That's determined by the interview. And as we start talking about what the job requirements are, the interaction, the conversation, they'll be able to say, "Oh yes, I can do that because my experience... I did this." And you can see that. There's a lot of follow-through and...

P7 explained how she was interviewed as an example,

Then I came in and was interviewed by HR, and then I was... Well, I was interviewed by the consultant, I was interviewed by HR, then I was interviewed by the executive director, and then they all decided. It was a long process.

P8 explained how interviews were important for the hiring process,

And I think... It's interesting, I hear from the residents a lot that they feel somehow we have a knack of hiring people who have really nice dispositions. And they actually have commented, "How does it always happen?" So somehow... And maybe that's ambiguous that you can't really put your hand on it, but somehow it comes through in the interview process. 
A review of the research site's employment application appears to be in a standard format. Many veterans may not know how to structure a resume that presents their military knowledge, skills, and abilities. Hiring managers use resumes to identify potential candidates for interviews. A poorly designed resume could be a serious flaw in a job search.

As a result, the data analysis, two subthemes emerged with regard to the specific recruitment and interview protocol: (a) hiring managers do not do anything differently for veterans, and (b) hiring managers ensure potential hires are reliable and responsible.

Subtheme 1: Hiring managers do not do anything differently for veterans. This subtheme defined as hiring managers indicating that they do not do anything differently for veterans when recruiting, selecting, or hiring for a position. Participants mentioned this subtheme eight times in six interviews. When asked, "What strategies and techniques have you used to bridge the employability gaps regarding veterans?" P1 indicated, "I don't really think within the context of my unit that we've done anything." P2 stated,

When making my decision, the fact that an applicant is or is not a veteran will not necessarily influence that decision. In fact, only one applicant that I have interviewed was a veteran. My decision to hire her had to do more with her experience and qualifications for the position she applied for.

This subtheme was also evident in the following exchange with P4:

The job descriptions are pretty basic for the position. I mean, positions that probably require a degree, someone that's a veteran that has applied, but maybe their MOS in the military was relatable to that position, they would still be maybe considered, depending on how, the length of time that they were in experience. But otherwise, most of the positions here relatively straightforward. Nursing, you would have to have a license, dining services really, other things you don't have to, so really anyone who's interested or has prior experience or things like that would be considerable.

Christine: You just mentioned that the skills, the military skills, so when you post a position do you say equivalent to...

P4: Really, we don't. The only positions that we really require any kind of license or anything like that is mostly nursing, so that wouldn't really apply to setting it out that, "This would be equal to... " however compared to military experience. I'm sorry, haven't really run into that situation either.

P5 stated,

To be quite frankly honest, I've never had a veteran apply. So, that's a kinda tough one to answer. The only veteran I have ever had was a transfer from another facility, which... A lateral transfer from one facility to another is first choice before we hire any outside applicants.

Christine: So, in that case the military skill didn't play a part?

P5: It wouldn't have. It had been strictly on his evaluations within the company already. 
Somebody that's been here more than 90 days and has a good reputation and good evaluations can transfer from facility to facility.

In a final example of this subtheme, when asked, "What strategies and techniques have you used to bridge the employability gaps regarding veterans?" P7 stated,

I don't think that we necessarily reach out specifically for veterans, we reach out for the right candidate. So, regardless whether it's a veteran or not, everybody would be interviewed equally. Of course, everyone encourages veterans to apply.

This subtheme appears to show that while the participants perceive veterans in a positive manner, and that those veterans possess the necessary skills to succeed in the workplace, veterans do not have the same employment opportunities as non-veterans.

Subtheme 2: Hiring managers ensure potential hires are reliable and responsible. The participants mentioned this subtheme six times in three interviews. P4 described seeking candidate that are reliable,

Certain things we look for, like longevity. So, someone that's not skipping, a job hopper basically. So we look for that. Things I look at is, reasons why they left a company. On our application it does ask, "reason for desiring change" or "reason leaving." So, if it's things that's like, some people do disclose that they're fired, obviously those would be a red flag. If it's "personal" we'll bring them in for an interview and kind of question to figure it out, because there's different stories. Some people say "relocation" so things like that won't not have us bring them in. Only things like, they were fired, are red flags.

In another example, P5 noted,

I'd like to see veterans apply, you know? I would, like I said it's half the battle anymore, it's just having somebody that's dedicated and willing to show up. Training on the job, training, and skills to be learned in every facility is almost better when you can train them yourself. Half the battle anymore is just getting somebody to show up.

Finally, P6 stated, "I'm looking for responsibility, accountability [in a job candidate]."

This subtheme appeared to show the difficulty facing a hiring manager as reliability and responsibility are attributes that are only measurable in hindsight. While prior actions may be a guide to future behavior, it is rarely possible to guarantee that this behavior will continue. According to Oladapo (2014), it is very important to ensure that the assessment tools used to establish applicants' reliability and responsibility are genuine measures of those competencies. When determining an applicant's reliability and responsibility, hiring managers could use the applicant's previous work experience as a general measure of reliability and responsibility (Jonsson \& Rancano, 2013). For this, there are structured tools, such as government websites, to help hiring managers determine how military jobs and their associated knowledge, skills and abilities can translate to the requirements of the civilian workforce.

\section{Theme C: Veterans Have Skills from Military Training}

The third theme was hiring managers recognize that veterans have skills from military 
training. The review of the academic literature detailed information on credentials related to a military occupational specialty. According to Harrell and Berglass (2012), hiring managers have suggested that military veterans have many positive skills such as discipline, leadership, and teamwork. The third question asked was, how might the KSAs of a veteran strengthen your organization for a qualifying position? Analyzing the participants' responses and comparing the responses with the academic literature, all the eight participants provided the consensus that veterans have leadership skills, people skills, and communication skills; they are trainable, willing to work, and willing to learn; and, they are trustworthy, all of which are key indicators of employability. This was supported by the review of the academic literature about the military credentials. Two participants mentioned that they value veterans in a variety of ways two times. P2 shared, "Our organization employs many veterans, and we do include them in our Veteran's Day celebration with our residents." P3 discussed how the organization shows they value veterans,

One thing we do here is every year; we honor our resident and employee veterans. Every year on Veterans Day, we invite all of the residents that are veterans, their family members, and the employees that are veterans, to a special event to honor them and thank them for what they have done. So maybe it's indirectly answering the question, but it is something that we do value. What the veterans do for us and have done for us, and we do have an annual event to recognize that. So, maybe it may not be a strategy in the direct hiring process. However, as people tell their friends, they really do respect us and that's nice for our company. A word for our company out there in the community for our veteran.

This theme related to organizational leaders essential for retaining veterans. As mentioned previously, the participants perceive veterans in a positive manner. The participants did not appear to recognize any relationship between their positive perception of that military experience with the possible need to adjust their hiring criteria to take into account that military language and experience.

As a result, the data analysis, three subthemes emerged from veterans' knowledge, skills, and abilities: (a) veterans are disciplined and responsible, (b) veterans have leadership skills, and (c) veterans can work with a team.

Subtheme 1: Veterans are disciplined and responsible. This subtheme refers to hiring managers' perceptions that veterans are disciplined and responsible. Participants mentioned this subtheme eight times in six interviews. P4 exemplified this theme by saying,

It's honorable; I know we have had applicants who currently do Reserves. So you know it's nice with military. My family comes from a military background, they're very regimented, and they teach discipline, things like that. Responsibilities. So those kinds of things stick out when you see that, as well.

I think, probably, with the whole kind of idea of them being regimented, they're taught a certain kind of demeanor, and respect as well. Military people that I've come across, they tend to be very respectable, know how to kind of control their temperaments, and reliable just based off of the experiences that they've had. Kind of a little more motivated. 
P5 shared,

Me, personally, being a veteran, I know the regimen that that person is in with attention to detail, being able to follow or direct orders, just the whole mindset of a military background to me personally would give them a step above a non-military person,

P6 expressed views of veterans on the following manner

I have good experience with them, I have a soft heart for them, and they turn out to be great employees because they're already trained, they're accustomed to taking orders, they're accustomed to doing what they're supposed to be doing, so you don't have to babysit for them, and they already come with a very strong sense of integrity and loyalty, so there's half my job. If you can come in with that, I can teach you anything.

P7 felt similarly and stated,

I think, is affected by a military background, meaning that they understand commitment. They really understand policy and procedure. I think it's very easy to have discussions with, "Here's our vacation time or this... "And people comply with that more readily. It's a mindset that is fabulous. I love it, because they understand structure, they understand the order of things, and the order of things to get done. And there's a stick-to-it-ness. They get the job done. They stick to it till the job gets done. It's not like a lollygag sit-back; it's a person that has direction. And when I see that, it really, it stands out, it's a plus, it's a big plus.

Subtheme 2: Veterans have leadership skills. This subtheme refers to hiring managers' perceptions that veterans have leadership skills. Participants mentioned this subtheme six times in five interviews. P1 stated, "I could see that relating to the leadership skills in the military because you are confident in your abilities and can make those decisions." When reflecting upon a current employee who was in the military, P2 indicated, "She is disciplined, takes direction, and is a good leader when a situation arises that needs to be dealt with if I am unavailable." P3 explained,

Leadership, which I think is another positive asset that you see so often from those there in the military. Decision making in that they can make a decision if they see something that needs to be done they do. So I look for those qualities when I do interview someone. I think that does compare some of the knowledge, abilities, and skill set of those in the military.

P5 said that veterans have, "Leadership, dedication, Attention to detail." In a final example of this subtheme, P8 explained,

There's the skill sets of very specific task-oriented competencies and then there's the skill set of things that they may have learned in the military that would give them leadership, supervisory skills, etcetera. So, we do use those competencies as kind of a road map when we're doing hiring.

Subtheme 3: Veterans can work with a team. This subtheme refers to hiring managers' perceptions that veterans can work very well with a team. Participants mentioned this subtheme five times in four interviews. P3 explained, 
When comparing military skill sets I someone who has military, experience would be a team player, who would appreciate and help to enhance the camaraderie among the team. I would like see that we have a good team that's cohesive and works together well. It gives them more confidence in our organization, which will strengthen our organization when the general public and our clients feel that they're confident in what our employees do and can do.

P4 said, "They're spending time working together as a team, as a unit. So they might be able to bring teamwork, be able to rally people together, things like that." P6 mentioned,

So I have a veteran and I have a non-veteran. I'm thinking of my group of veterans right now, and if I present a new initiative. We're going to try something different because this is not working, maybe different showering techniques or whatever. I will get more buy-in from the veterans. They are more apt to try rather than... I don't get the grumbling and the, "Oh, this isn't going to work," or the talking behind the back.

In a final example of this subtheme, P8 stated, "Again, they understand chain of command. They understand the necessity to follow direction. They understand the importance of teamwork. All of those things are key in any organization."

This theme appears to show that the participants had little problem sharing the benefits of military skillsets when discussing them with the veteran. Hiring managers perceive veterans as having received a wealth of knowledge, skills, and competencies through practical military experience. This suggests that the problem lies not in the actual skills obtained by the veteran, but in the translation of the military language and describing those achievements into their civilian equivalent.

\section{Theme D: No Experience with Hiring Veterans}

The fourth theme was no experience with hiring veterans. This theme defined as hiring managers indicating that they have no experience with hiring veterans. Analyzing the participants' responses and comparing the responses with the academic literature, social identity theory is significant in the findings of theme four. Tajfel and Turner (1986) defined social identity theory as the connection of a group membership and the value significance placed on those group memberships. Veterans identify themselves as a unique and separate group. Likewise, civilian as a group compare themselves to veterans as a group (Gade \& Wilkins, 2013). Hiring managers use social identity stereotypes when making hiring and promoting decisions that can lead to unintended discrimination and biases in organizations (Guionate \& Fiske, 2003). The effects of social identity not only have a role in the applicant obtaining an interview, but can also influence the overall evaluation of the interview (Guionate \& Fiske, 2003). Stone and Stone (2015) posited that hiring managers with military experience would have a better understanding of the transferability of military knowledge, skills, and abilities to civilian jobs. Hiring managers who are not veterans may not understand military credentialing (Benmelech \& Frydman, 2014) that may lead to stereotypes and bias against veteran applicants. Two Participants when asked, "What strategies and techniques have you used to bridge the employability gaps regarding veterans?" P1 said, "I don't really think within the context of my unit that we've done anything." P5 shared, 
To be quite frankly honest, I've never had a veteran apply. So, that's a kinda tough one to answer. The only veteran I've ever had was a transfer from another facility, which... A lateral transfer from one facility to another is first choice before we hire any outside applicants.

Later, when asked, "What strategies and techniques have you used to bridge the employability gaps regarding veterans?" P5 stated, "Like I've said, I've never even had veterans apply. I never dealt with it."

This theme appears to show few surprises as a review of the organization's application for employment currently includes branch of service, date of entry, date of discharge, service schools, special training, or assignments. Many of the organizations' job announcements include title of the position and training requirements. According to Tas and Ergin (2012), hiring managers utilize job applications and resumes to acquire the best candidates within a pool of people that may benefit the organization. This appears to indicate a need for hiring managers to ensure that they clearly label vacancy announcements to include the equivalent military language or qualification.

\section{Discussion}

Overall, the research findings were consistent with the purpose of the study and related to both social identity theory and organizational theory. The central research question was what strategies, matrices, and techniques do hiring managers use to recruit, select, and hire veterans? The primary themes that emerged for this research question were (a) strategies used to fill open positions, (b) specific recruitment and interview protocols, (c) veterans have skills from military training, and (d) no experience with hiring veterans. The above themes played an important role in helping to understand the research phenomenon in addition to addressing the central research question.

The findings of the study indicated that hiring managers need hiring and recruitment strategies to hire veterans for organizational fit. According to Gramm and Schnell (2013), employment applications and job requirement matrices for a company position must include, among other details, years of experience, technical skills, and the level of education requirements. A review of the organization's application for employment includes branch of service, date of entry, date of discharge, service schools, special training, or assignments. Many of the organization's job announcements include title of the position and training requirements. This could indicate a need for hiring managers to ensure that the title training for all vacancy were clearly visible.

The conceptual frameworks for this research were social identity theory and organizational change theory. The participants' responses and company hiring documents supported social identity theory and organizational change theory. Understanding social identity and enacting organizational changes in hiring and recruitment strategies targeted at creating diverse workers are areas beneficial for organizations and can affect corporate profits and earnings (Farndale et al., 2015). The hiring and recruitment strategies of an organization are important for hiring managers whose goals are finding the right workers to increase company effectiveness (Bottger \& Barsoux, 2012). 
To examine this obvious need for hiring strategies, I reviewed multiple literatures to outline the connection between social identity theory and hiring practices. When matching an applicant to a job, human resource managers possess an awareness of the applicant's social identity (Gholston, 2015). This is important because social identity theory highlights issues such as bias and stereotyping during the interview process (Rivera, 2012). Stereotypes and bias can influence the human resource manager's hiring decision without the person's knowledge (Gholston, 2015). Using social identity can assist hiring managers in the hiring and recruiting of veterans to eliminate the barriers in veterans' employability and development diversity in the workplace. Diversity training involves initiatives designed to aid in positive interpersonal interactions across social identity groups in reducing discrimination and bias toward various groups (Rivera, 2012). P5 noted, "I have never had a veteran apply." The data from the participants' response and the company's documentation revealed that hiring managers could create detailed categories and military terminology in their job descriptions to attracts veterans.

Lewin's (1951) three stages of organizational change played a key role in the evolution of organizational development that includes human resources development and communication: (a) unfreezing technique reduces residence to change; (b) moving technique involves developing new behavior and attitude through training; and (c) refreezing technique return the organization to a new state of stability. The findings of the study indicated that organizational change theory need for change is an essential strategy within organizations (Eastman, 2012). When asked "What strategies and techniques have you used to bridge the employability gaps regarding veterans?" P8 said,

Probably not nearly enough. We haven't done, to the best of my knowledge; HR per se has not worked with our local veterans organizations, etcetera, to attend job fairs, to see if there might be jobs that we could train people up for, etcetera.

This response from the study indicated that building from Lewin's (1951) concept of change might help hiring managers mitigate veterans' employment challenges. Hiring managers need to implement a change in their recruitment and hiring strategy in order to bridge the gap with employers and transitioning veterans. Implementing changes in the recruitment and hiring strategy by working to describe and define new job description to include military culture and experience could increase recruitment and hiring of veterans.

\subsection{Practical Application}

The research findings on what are important to hiring managers relative to the employability of veterans is an important indicator of what organizational leaders should do when thinking about their organizational strategies. The consensus of the participants was that veterans have leadership skills, and communication skills; are trainable, are willing to learn, and willing to work; and are trustworthy; which are vital indicators of employability. I anticipate the current study may fill gaps in business knowledge required for the hiring of veterans. More than 200 different military skills have a direct civilian job equivalent (Beauchesne \& O'Hair, 2013). Hiring managers should ensure their job application and recruiting processes are veteran friendly. In a process similar to that in which college graduate produces an academic 
credential as proof of a degree, hiring managers should request a veteran's DD214 as proof of service completion. The DD214 confirms military occupational training, military education, badges, decorations, citations, medals, and campaign awards. Gadermann et al., (2014) confirmed that military occupational training and experience are similar to college students' or other providers of training.

The results of the study could enable hiring managers to review their diversity strategies, and possibly increasing levels of recruitment and hiring of veterans by creating detailed job descriptions that include military language. Organizational leaders should provide hiring managers with the training to understand hiring strategies that include tools and education about how military skills relate or can be adapted to civilian careers. In addition, organizational leaders could provide training for hiring managers to access credible resources such as job fairs, to look for qualified veterans; and the tools needed to visit government websites to help determine how military skillsets can translate to the requirements of the civilian workforce.

There are federal and state tax incentives for organization to hire veterans. Hiring managers should be educated in the availability and awareness of government incentives. These incentives for private sector businesses to hire veterans put amenities into effect to provide veterans with advantages for reemployment, while at the same time giving veterans protection from discrimination (Parker, 2012).

Unemployment population negatively affects the U.S. economy (Faberman \& Foster, 2013). According to Karren and Sherman (2012), unemployed workers are a stigmatized group and the inability to secure employment may only intensify this stigma. Recruitment strategies and hiring practices contribute to the high unemployment rate among skilled veterans moving to civilian employment (Fogle, 2012). The finding of the study confirmed that employers do not do anything differently for veterans when recruiting, selecting, or hiring for a position. The findings also showed that hiring managers have no experience with the transferability of military skills when juxtaposed with the talent requirements of civilian positions. Hiring managers need to know and implement strategies and techniques to help with licensing or certification so that veterans can use the skills learned in the military. Hiring managers may consider evaluating their hiring and recruiting strategies against the main themes listed above, which are essential strategies all organizations can use in the employment of veterans. Understanding the result of this study could be helpful in addressing the recruitment policies and hiring practices of organizations allowing them to integrate the military culture, language, and skillsets transferable into the civilian workplace; garnering a competitive advantage. I will disseminate the result of this study through scholarly and business journals.

The research findings confirmed that civilian employers find it difficult to translate or understand military culture, language, and job skills, and the high rate of veterans' joblessness reflect this lack of translation ability or cultural understanding. The themes derived from participants' interviews and organizational documents shows that hiring managers should ensure potential hires have relevant experience and qualifications by making clear and accessible links to discover the competencies and strengths that a role 
requires. Also, hiring managers should be trained in the techniques of interviewing veterans who are identified as potential hires. Hiring managers should explore recruiting and hiring veterans from job fairs and vocational rehabilitation and employment programs (VR\&E). Employers hiring veterans from VR\&E programs may be eligible for tax credits, on-the-job training, and/or special employer incentives (Parker, 2012). Organizational leaders should reevaluate their existing recruiting and hiring strategies and strengthen or implement new strategies that focus on coaching hiring managers as to how military skills relate to or can be explained and adapted, for civilian careers. Since hiring managers verify certification or licenses, there is the need for congress to improve the military transition assistance programs to generate jobs and give veterans the necessary credentials and/or certification needed to succeed in the civilian world.

\subsection{Limitations}

Consider the following limitations when interpreting the results of the study. I used a single case study to explore the recruitment and hiring of applicants and the strategies and techniques used to map the skills of veterans to open positions within a midsized privately held organization. The population consisted of eight hiring managers with at least one year of hiring experience. Although this study provides rich, in-depth descriptive information about the recruitment strategies, matrices, and techniques used in hiring veterans the number of participants were small.

\subsection{Recommendations for Action}

The purpose of the qualitative single case study was to identify strategies, matrices, and techniques business hiring managers use to recruit, select, and hire veterans, and to realize how these strategies and techniques affect the hiring of veterans. The research findings confirmed that civilian employers find it difficult to translate or understand military culture, language, and job skills, and the high rate of veterans' joblessness reflect this lack of translation ability or cultural understanding. The themes derived from participants' interviews and organizational documents shows that hiring managers should ensure potential hires have relevant experience and qualifications by making clear and accessible links to discover the competencies and strengths that a role requires. Also, hiring managers should be trained in the techniques of interviewing veterans who are identified as potential hires. Hiring managers should explore recruiting and hiring veterans from job fairs and vocational rehabilitation and employment programs (VR\&E). Employers hiring veterans from VR\&E programs may be eligible for tax credits, on-the-job training, and/or special employer incentives (Parker, 2012). Organizational leaders should reevaluate their existing recruiting and hiring strategies and strengthen or implement new strategies that focus on coaching hiring managers as to how military skills relate to or can be explained and adapted, for civilian careers. Since hiring managers verify certification or licenses, there is the need for congress to improve the military transition assistance programs to generate jobs and give veterans the necessary credentials and/or certification needed to succeed in the civilian world. Lastly, disseminate the findings of the study to business journals, business organizations, and the VA.

\subsection{Recommendation for Future Study}


Recommendation for further study include for a larger sample size or equal sampling of different industries to confirm or negate the results of this research (Robinson, 2014). Another limitation for this study was that the study solely focused on one corporation. Future researchers can also explore more than one firm. A multiple case study design could afford researchers the opportunity to explore more than one organization for the opportunity for literal replication of the results. I conducted the study in the Upper Hudson Valley region of New York State; future researcher may focus on other geographical locations in the United States.

\section{Conclusion}

Hundreds of thousands of Gulf War-era II veterans already unemployed with more United States soldiers expected to leave the military by the end of the 2016 (Ryan, Carlstrom, Hughey, \& Harris, 2011). With the challenges of returning to civilian life, Gulf War-era II veterans are facing an uncertain economic future. The purpose of the qualitative single case study was to explore critical aspects of hiring managers' decision-making process, and to realize how these strategies and techniques affect the hiring of veterans. Firstly, study findings confront the recruitment policies, and hiring practices of organizations to integrate the military culture, language, and skillsets that are transferable into the civilian workplace. Secondly, the findings of the study indicate the need for the Congress of the United States to improve the military transition programs to create jobs and give veterans the necessary certification needed to succeed in the civilian workplace.

Participants provided the consensus that veterans have leadership skills, people skills, and communication skills; they are trainable, willing to work, and willing to learn; and, they are trustworthy, all of which are key indicators of employability. The finding of the study confirmed that hiring managers need amended recruitment processes and hiring strategies to hire veterans for organizational fit. The findings of the study also confirmed that civilian employers find it difficult to translate or understand military culture, language, and job skills, a situation that has contributed to the high rate of veteran's joblessness. The social impact of the study could help hiring managers to identify and design the required job description criteria to include the transferable skills of veterans. The study results may contribute to awareness of what employers are seeking that the veteran population may be able to fulfill, and what potential issues may need consideration.

\section{References}

Adler, A.B., \& Castro, C.A. (2013). An occupational mental health model for the military. Military Behavioral Health, 1, 41-45. doi:10.1080/21635781.2012.721063

Ali, A., \& Yusof, H. (2011). Quality in qualitative studies: The case of validity, reliability and generalizability. Issues in Social and Environmental Accounting, 5, 25-64. Retrieved from http://www.iiste.org/Journals/index.php/ISEA/index

Ashforth, B. E., Harrison, S. H., \& Corley, K. G. (2008). Identification in organizations: An examination of four fundamental questions. Journal of Management, 34, 325-374. doi: $10.1177 / 0149206308316059$ 
Avery, D., McKay, P., \& Wilson, D. (2008). What are the odds? How demographic similarity affects the prevalence of perceived employment discrimination. Journal of Applied Psychology, 93, 235-249. doi:10.1037/0021-9010.93.2.235

Bailey, A. K. (2011). Race, place, and veteran status: Migration among Black and White men, 1940-2000. Population Research and Policy Review, 30, 701-728. doi:10.1007/s11113-011-9207-4

Bangerter, A., Gravely, A., Cutting, A., Clothier, B., Spoont, M., \& Sayer, N. (2010). Brief report: Comparison of methods to identify Iraq and Afghanistan war veterans using Department of Veterans Affairs administrative data. Journal of Rehabilitation Research \& Development, 47, 815-821. doi:10.1682/JRRD.2009.08.0115

Beauchesne, K., \& O'Hair, J. R. (2013). Investing in vets: Strategies to help returning gulf war vets enter the civilian work force successfully. Social Work in Mental Health, 11, 434-459. doi:10.1080/15332985.2013.804021

Bell, R. L., \& Bodie, N. L. (2012). Leaders as catalysts for organizational change: How popular press business books address this topic. Journal of Organizational Culture, Communications and Conflict, 16(1), 49-70. Retrieved from http://www.alliedacademies.org/public/journals/JournalDetails.aspx?jid=11

Benmelech, E., \& Frydman, C. (2014). Military CEOS. Journal of Financial Economics. 117(1), 43-59. doi:10.1016/j.jfineco.2014.04.009

Bergerson, A. A., \& Huftalin, D. (2011). Becoming more open to social identity-based difference: Understanding the meaning college students make to this movement. Journal of College Student Development, 52, 377-395. doi:10.1353/csd.2011.0055

Bernard, H. R. (2013). Social research methods: Qualitative and quantitative approaches (2nd ed.). Thousand Oaks, CA: Sage

Bilewicz, M., \& Kofta, M. (2011). Less biased under threat? Self-verificatory reactions to social identity threat among groups with negative self-stereotypes. Journal of Applied Social Psychology, 41, 2249-2267. doi:10.1111/j.1559-1816.2011.00802.x

Block, C. J., Koch, S. M., Liberman, B. E., Merriweather, T. J., \& Roberson, L. (2011). Contending with stereotype threat at work: A model of long-term responses. The Counseling Psychologist, 39, 570-600. doi:10.1177/0011000010382459

Bottger, P. \& Barsoux. J. L. (2012). Masters of fit: How leaders enhance hiring. Strategy \& Leadership, 40(1), 33-39. doi:10.1108/10878571211191684

Bowman, L. (2011). Americans with Disabilities Act as amended: Principles and practice. New Directions for Adult \& Continuing Education, 2011(132), 85-95. doi:10.1002/ace.434

Brewer, M. B. (2001). The many faces of social identity: Implications for political psychology. Political Psychology, 22(1), 115-125. doi:10.2307/3791908

Brown, P. A., \& Gross, C. (2011). Serving those who have served-Managing veteran and 
military student best practices. The Journal of Continuing Higher Education, 59(1), 45-49. doi:10.1080/073377363.2011.544982

Bullock, E. E., Braud, J., Andrews, L., \& Phillips, J. (2009). Career concerns of unemployed U.S. war veterans: Suggestions from a cognitive information processing approach. Journal of Employment Counseling, 46, 171-181.

doi:10.1002/j.2161-1920.2009.tb00080.x

Cannella, A. A., Jones, C. D., \& Withers, M. C. (2015). Family-versus lone-founder-controlled public corporations: Social identity theory and boards of directors. Academy of Management Journal, 58, 436-459. doi:10.5465/amj.2012.0045

Capehart, B., \& Bass, D. (2012). Review: Managing posttraumatic stress disorder in combat veterans with comorbid traumatic brain injury. Journal of Rehabilitation Research \& Development, 49, 789-812. doi:10.1682/JRRD.2011.10.0185

Chamberlin, C. (2010). Cultivating leadership at every level of your organization, Strategic Finance, 2(21). Retrieved from http://www.imanet.org/resources_and_publications/strategic_finance_magazine.aspx

Christensen, C. M., Marx, M., \& Stevenson, H. H. (2006). The tools of cooperation and change. Harvard Business Review, 84, 73-80. Retrieved from http://www.hbr.org/

Christian, B. (2012). Hire a hero, enjoy the benefits. Journal of Accountancy, 213, 54-57. Retrieved from http://journalofaccountancy.com

Clarke, R., \& Cohen, D. (2010). Sierra Pacific resources implement a merger. Journal of International Academy for Case Studies, 16, 83-95. Retrieved from http://www.alliedacademies.org

Cole, M. S., Rubin, R. S., Feild, H. S., \& Giles, W. F. (2007). Recruiters' perceptions and use of applicant résumé information: Screening the recent graduate. Applied Psychology: An International Review, 56, 319-343. doi:10.1111/j.1464-0597.2007.00288.x

Cowan Sahadath, K. (2011). Leading change one conversation at a time: A phenomenographic study of senior leadership conversations. Dissertation Abstracts International, 71, 2663. Retrieved from http://phdtree.org/

Cullen, K. L., Edwards, B. D., Casper, W. C., \& Gue, K. R. (2014). Employees' adaptability and perceptions of change-related uncertainty: Implications for perceived organizational support, job satisfaction, and performance. Journal of Business and Psychology, 29, 269-280. doi:10.1007/s10869-013-9312-y

Damico, J. S., \& Ball, M. J. (2010). Prolegomenon: Addressing the tyranny of old ideas. Journal of Interactional Research in Communication Disorders, 1(1), 1-29.

doi:10.1044/1058-0360(2011/ed-03)

Dawson, M., Burrell, D., \& Rahim, E. (2010). Deep dive into understanding the theory of 
military organization, military leadership, skill transfer, aspects of program management, and decision support systems. Journal of Global Intelligence and Policy 3, 5-17. Retrieved from http://www.intellectbase.org

Deaux, K., \& Burke, P. (2010). Bridging identities. Social Psychology Quarterly, 73, 315-320. doi:10.1177/0190272510388996

Demuijnck, G. (2009). Non-discrimination in human resources management as a moral obligation. Journal of Business Ethics, 88, 83-101.

doi:10.1007/s10551-009-0100-6

Denzin, N. K., \& Lincoln, Y. S. (2011). The Sage handbook of qualitative research (4 $\left.{ }^{\text {th }} \mathrm{ed}.\right)$. Thousand Oaks, CA: Sage.

Dovidio, J. F., Gaertner, S. E., Kawakami, K., \& Hodson, G. (2002). Why can't we just get along? Interpersonal biases and interracial distrust. Cultural Diversity and Ethnic Minority Psychology, 8, 88-102. doi:10.1037/1099-9809.8.2.88

Eastman, C. A. (2012). Working with Toshiba, Lewin and Dewey: A journey into the heard of change. Higher Education, Skills and Work-Based Learning, 2, 132-140. doi: $10.1108 / 20423891211224612$

Faberman, R., \& Foster, T. (2013). Unemployment among recent veterans during the Great Recession. Economic Perspectives, 37(1), 1-13. Retrieved from http://chicagofed.org/webpages/publications/economic_perspectives/index.cfm

Farndale, E., Biron, M., Briscoe, D. R., \& Raghuram, S. (2015). A global perspective on diversity and inclusion in work organisations. The International Journal of Human Resource Management, 26(6), 677-687. doi:10.1080/09585192.2014.991511.

Festinger, L. (1954). A theory of social comparison processes. Human Relations, 7(2), 117-140. doi:10.1177/001872675400700202

Fogle, C. (2012). Employers' perceptions of business graduates from historically Black colleges and universities. Global Education Journal, 12(1), 11-70. Retrieved from http://www.franklinpublishing.net/globaleducation.html

Gade, D. M., \& Wilkins, V. M. (2013). Where did you serve? Veteran identity, representative bureaucracy, and vocational rehabilitation. Journal of Public Administration Research and Theory, 23, 267. doi:10.1093/iopart/mus030

Gadermann, A. M., Heeringa, S. G., Stein, M. B., Ursano, R. J., Colpe, L. J., Fullerton, C. S., \& ... Kessler, R. C. (2014). Classifying U.S. army military occupational specialties using the occupational network. Military Medicine, 197(7), 752-761.

doi:10.7205/MILMED-D-13-00446

Gati, I., Ryzhik, T., \& Vertsberger, D. (2013). Preparing young veterans for civilian life: The effects of a workshop on career decision-making difficulties and self-efficacy. Journal of 
Vocational Behavior, 83, 373-395. doi:10.1016/j.jvb.2013.06.001

Gelo, O. C. G., Salcuni, S., \& Colli, A. (2012). Text analysis within quantitative and qualitative psychotherapy process research: Introduction to special issue. Research in Psychotherapy, 15, 45-53. doi:10.7411/RP.2012.005

Gibson, J. W., Jones, J. P., Cella, J., Clark, C., Epstein, A., \& Haselberger, J. (2010). Ageism and the baby boomers: Issues, challenges and the TEAM approach. Contemporary Issues in Education Research (CIER), 3(1), 53-60. Retrieved from http://journals.cluteonline.com/index.php/CIER

Gholston, S. (2015). Effective strategies for hiring employees despite social affiliation. Academic Journal of Interdisciplinary Studies, 4(2), 211. doi:10.5901/ajis.2015.v4n2p211

Gramm, C. L., \& Schnell, J. F. (2013). Does employment security influence organizational hiring success? International Journal of Business and Social Science, 4(3), 23-32. Retrieved from http://www.ijbssnet.com

Greenwald, J. (2012). Soldiers return to civilian jobs. Business Insurance, 46, 1-20. Retrieved from http://www.businessinsurance.com/

Griffith, J. (2010). Citizens coping as soldiers: A review of deployment stress symptoms among reservists. Military Psychology, 22, 176-206. doi:10.1080/08995601003638967.

Guinote, A. \& Fiske, S.T. (2003). Being in the out-group territory increases stereotypic perceptions of outgroups: Situational sources of category activation. Group Processes and Intergroup Relations, 6, 323-334. doi:10.1177/13684302030064001

Hagen, W. (2011). Dissection and analysis of the recent cases on employment discrimination under Title VII of the Civil Rights Act of 1964. Employee Responsibilities \& Rights Journal, 23, 171-186. doi:10.1007/s10672-010-9163-x.

Hanafizadeh, P., \& Osouli, E. (2011) Process selection in re-engineering by measuring degree of change. Business Process Management Journal, 17, 284-310. doi:10.1108/14637151111122356

Harper, M., \& Cole, P. (2012). Member checking: Can benefits be gained similar to group therapy? The Qualitative Report, 17, 510-517. Retrieved from http://www.nova.edu/ssss/

Harrell, M. C., \& Berglass, N., 2012. Employing American veterans: Perspectives from business. Washington, DC: Center for New American Society.

Harvey, L. (2014). Beyond member-checking: A dialogic approach to the research interview. International Journal of Research \& Method in Education, 38, 23-38. doi:10.1080/1743727X.2014.914487

Hays-Thomas, R., Bowen, A., \& Boudreaux, M. (2012). Skills for diversity and inclusion in organizations: A review and preliminary investigation. The Psychologist-Manager Journal, 15, 128-141. doi:10.1080/10887156.2012.676861 


\section{Ml Macrothink}

International Journal of Human Resource Studies

ISSN 2162-3058

2017, Vol. 7, No. 2

Heilman, M. 1983. Sex bias in work settings: The lack of fit model. In B. M. Staw \& L. L. Cummings (Eds.), Research in organizational behavior, 5, 269-298. Greenwich,CT: JAI Press.

Herring, C. (2009). Does diversity pay? Race, gender, and the business case for diversity. American Sociological Review, 74, 208. doi:10.1177/000312240907400203

Hogan, R., Chamorro-Premuzic, T., \& Kaiser, R. B. (2013). Employability and career success: Bridging the gap between theory and reality. Industrial \& Organizational Psychology, 6(1), 3-16. doi:10.1111/iops. 12001

Homburg, C., Klarmann, M., Reimann, M., \& Schilke, O. (2012). What drives key informant accuracy? Journal of Marketing Research, 49, 594-608. doi:10.1509/jmr.09.0174

Hudson Valley Gateway Chamber of Commerce. (2013). Member directory. Retrieved from https://www.hvgatewaychamber.com/directory/A

Institute of Medicine. (2010). Returning home from Iraq and Afghanistan: Preliminary assessment of readjustment needs of veterans, service members, and their families. Washington, DC: The National Academies Press.

Jones, J., \& Lewis, D. (2011). Let's not go down that path again: Lessons from the past applied to immigrant-targeted discrimination. Employee Responsibilities \& Rights Journal, 23, 229-247. doi:10.1007/s10672-010-9161-z

Jonsson, J. E. \& Rancano, A. (2013). Hiring employees that fit with a proactive approach. International Journal of Business and Social Science, 4, 106-114. Retrieved fromhttp://www.ijbssnet.com

Karren, R., \& Sherman, K. (2012). Layoffs and unemployment discrimination: A new stigma. Journal of Managerial Psychology, 27(8), 848-863. doi:10.1108/02683941211280148

Kleykamp M. (2009). A great place to start? The effect of prior military service on hiring. Armed Forces \& Society. 35, 266-285. doi:10.1177/0095327x07308631

Klusek, L., \& Bornstein, J. (2006). Information literacy skills for business careers -Matching skills to the workplace. Journal of Business Finance Librarianship, 11, 3-21. doi:10.1300/J109v11n04_02.

Kotter J. (1996). Leading change. Boston, MA: Harvard Business School Press.

Kulik, C., Roberson, L., \& Perry, E. L. (2007). The multiple-category problem: Category activation and inhibition in the hiring process. Academy of Management Review, 32, 529-548. doi:10.5465/AMR.2007.24351855

LeardMann, C. A., Powell, T. M., Smith, T. C., Bell, M. R., Smith, B., Boyko, E. J.,...Hoge, C. W. (2013). Risk factors associated with suicide in current and former US military personnel. Journal of American Medical Association, 310, 496-506. doi:10.1001/jama.2013.65164 
Leigh, J. M., Shapiro, E. R., \& Penney, S. H. (2010). Developing diverse, collaborative leaders: An empirical program evaluation. Journal of Leadership \& Organizational Studies 17, 370-379. doi:10.1177/1548051809355510

Lewin, K. (1951). Field theory in social science. New York, NY: Harper Collins.

Major, B. (2012). Self, social identity, and stigma: Through Kay Deaux's lens. In S. Wiley, G. Philogène, T. A. \& Revenson (Eds.), Social categories in everyday experience (pp. 11-30). Washington, DC: American Psychological Association. doi:10.1037/13488-001

Maldonado., J. (2011). The legacy of a president: An analysis of the Civil Rights Act of 1964. Journal of US-China Public Administration, 8, 704-711. Retrieved from http://davidpublishing.org/journals_info.asp?jId=599

Malos, S. (2015). Overt stereotype bias and discrimination in the workplace: Why haven't we fixed this by now? Employee Responsibilities and Rights Journal, 27: 271-280. doi:10.1007/s10672-015-9264-7

Maon, F., Lindgreen, A., \& Swaen, V. (2009). Designing and implementing corporate social responsibility: An integrative framework grounded in theory and practice. Journal of Business Ethics, 87, 71-89. doi:10.1007/s10551-008-9804-2

Migliaccio, J. N. (2013). Urban myths, baby boomers, and the effective financial professional. Journal of Financial Service Professionals, 67, 33-40. Retrieved from http://www.financialpro.org/pubs/journal_index.cfm

Muldoon, O. T., \& Lowe, R. D. (2012). Social identity, groups, and post-traumatic stress disorder. Political Psychology, 33, 259-273. doi:10.1111/j.1467-9221.2012.00874.x

Mwangi, G. K., Olayo, J. O., \& Simuyu, A. N. (2015). Employee skills, management style and organizational culture in implementation of strategic plans in middle level colleges in thika sub-county, Kenya. International Journal of Business and Management, 10(6), 199-207. doi:10.5539/ijbm.v10n6p199

Neuman, W. L. (2011). Basics of social research: Qualitative and quantitative approaches. Upper Saddle River, NJ: Prentice Hall.

Northouse, P. (2010). Leadership: Theory and practice (5th ed.). Thousand Oaks, CA: Sage Publications.

O’Brien, G. V., \& Brown, M. S. (2009). Persons with mental illness and the Americans with disabilities act: Implications for the social work profession. Social Work in Mental Health, 7, 442-457. doi:10.1080/15332980802536870

O'Fallon, M., \& Butterfield, K. (2012). The Influence of unethical peer behavior on observers' unethical behavior: A Social cognitive perspective. Journal of Business Ethics, 109, 117-131. doi:10.1007/s10551-011-1111-7

Ogles, D. (2012). Life during (and after) wartime: Enforceability of waivers under USERRA. The University Of Chicago Law Review, (1), 387. doi:10.2307/41552905 
Oladapo, V. (2014). The impact of talent management on retention. Journal of Business Studies Quarterly, 5(3), 19-36. Retrieved from http://jbsq.org

Onwuegbuzie, A. J., Leech, N. L., Slate, J. R., Stark, M., Sharma, B., Frels, R.,...Combs, J. P. (2012). An exemplar for teaching and learning qualitative research. Qualitative Report, 17(1), 16-77. Retrieved from http://www.nova.edu/ssss/QR

Pager, D., Bonikowski, B., \& Western, B. (2009). Discrimination in a low-wage labor market: A field experiment. American Sociological Review, 74, 777-799. doi:10.1177/000312240907400505

Parker, Y. (2012). VOW to hire veterans offers new incentives for employers and expanded benefits for veterans. Employment Relations Today (Wiley), 39, 27-37. doi:10.1002/ert.21362

Pate, R. L. (2011). Reemployment under USERRA sections 4312 \& 4313: At will employment vs. temporary employment. Contemporary Readings In Law \& Social Justice, 3(1), 82-98. Retrieved from http://www.addletonacademicpublishers.com/contemporary-readings-in-law-and-social-justic e

Pearce II, J. A. (2013). Using social identity theory to predict managers' emphases on ethical and legal values in judging business issues. Journal of Business Ethics, 112, 497-514. doi:10.1007/s10551-012-1274-x

Pearson, A. R., Dovidio, J. F., \& Gaertner, S. L. (2009). The nature of contemporary prejudice: Insights from aversive racism. Social and Personality Psychology Compass, 3, 314-338. doi:10.1111/j.1751-9004.2009.00183.x

Perl, L. (2011, November 29). CRS report for Congress: Veterans and homelessness. Retrieved from http://www.fas.org/sgp/crs/misc/RL34024.pdf

Persyn, J. M., \& Polson, C. J. (2012). Evolution and influence of military adult education. New Directions For Adult \& Continuing Education 2012(136), 5-16. doi:10.1002/ace.20031

Portillo, J., \& Block, W. (2012). Anti-discrimination laws: Undermining our rights. Journal of Business Ethics, 109, 209-217. doi:10.1007/s10551-011-1120-6

Ra'ees, W. (2010). Obama's Afghanistan strategy: A policy of balancing the reality with the practice. Journal of Politics \& Law, 3, 80-93. Retrieved from http://ccsenet.org/journal/index.php/jpl

Reddin, W. J., \& Stuart-Kotze, R. (1972). Effective situational diagnosis. Fredericton, Canada: W.J. Reddin and Associates.

Rivera, L. A. (2012). Hiring as cultural matching: The case of elite professional service frms. American Sociological Review, 77(6), 999-1022. doi:10.1177/0003122412463213

Robinson, O. C. (2014). Sampling in interview- based qualitative research: A theoretical and practical guide. Qualitative Research in Psychology, 11(1), 25-41. doi:10.1080/14780887.2013.801543 
Ruggs, E., Hebl, M., Walker, S., \& Fa-Kaji, N. 2014. Selection biases that emerge when age meets gender. Journal of Managerial Psychology, 29: 1028-1043. doi:10.1108/JMP-07-2012-0204

Ryan, S.W., Carlstrom, A.H., Hughey, K.F., \& Harris, B.S. (2011). From boots to books: Applying Schlossberg's model to transitioning America veterans. NACADA Journal, 31(1). doi:10.12930/0271-9517-31.1.55

Sayer, N., Spoont, M., Murdoch, M., Parker, L., Hintz, S., \& Rosenheck, R. (2011). A qualitative study of U.S. veterans' reasons for seeking Department of Veterans Affairs disability benefits for posttraumatic stress disorder. Journal Of Traumatic Stress, 24, 699-707. doi:10.1002/jts.20693

Seal, K. H., Bertenthal, D., Maguen, S., Gima, K., Chu, A., \& Marmar, C. R. (2008). Getting beyond "don't ask; don't tell": An evaluation of U.S. Veterans Administration post deployment mental health screening of veterans returning from Iraq and Afghanistan. American Journal of Public Health, 98, 714-720. doi:10.2105/AJPH.2007.115519

Shanley, C. (2007). Managing change through management development: An industry case study. The Journal of Management Development, 26, 962-979. doi:10.1108/02621710710833414

Shirey, M. R. (2011). Addressing strategy execution challenges to lead sustainable change. Journal of Nursing Administration, 41(1), 1-4. doi:10.1097/NNA.0b013e318200288a

Simpson, A., \& Armstrong, S. (2009). From the military to the civilian work force: Addressing veteran career development concerns. Career Planning \& Adult Development Journal, 25(1), 177-187. from http://www.questia.com/library/p142247/career-planning-and-adult-development-journal

Sloan, T. (2013). Distributed leadership and organizational change: Implementation of a teaching performance measure. The New Educator, 9(1), 29-53, doi:10.1080/1547688X.2013.751313

Stahl, L. (Correspondent). (2008, November 2). 60 Minutes [Television broadcast]. Washington, DC: CBS News. Retrieved from http://www.cbsnews.com/videos/coming-home/

Stare, A. (2010). Comprehensive management of project changes. Economic and Business Review for Central and South - Eastern Europe, 12, 195-210. Retrieved from http://web.lib.aalto.fi/en/journals/?cmd=show\&o=journal\&journalid=6662

Stone, C. \& Stone., D.L. (2015). Factors affecting hiring decisions about veterans. Human Resource Management Review, 25, 68-79. doi:10.1016/j.hrmr.2014.06.003

Suri, H. (2011). Purposeful sampling in qualitative research synthesis. Qualitative Research Journal, 11, 63-75. doi:10.3316/QRJ1102063

Tajfel, H., \& Turner, J. C. (1986). The social identity theory of inter-group behavior. Chicago, IL: Nelson-Hall. 
Tas, A., \& Ergin, E. A. (2012). Key factors for student recruitment: The issue of university branding. International Business Research, 5, 146-153. doi:10.5539/ibr.v5n10p146

Teachman, J. (2011). Are veterans healthier? Military service and health at age 40 in the all-volunteer era. Social Science Research, 40(1), 326-335. doi:10.1016/j.ssresearch.2010.04.009

Teal, C., Gill, A., Green, A., \& Crandall, S. (2012). Helping medical learners recognise and manage unconscious bias toward certain patient groups. Medical Education, 46(1), 80-88. doi:10.1111/j.1365-2923.2011.04101.x

Teelken, C., \& Watson, M. (2014). Coping strategies of professionals in emerging change processes: An empirical view. Journal of Change Management, 14(4), 429-433. doi:10.1080/03075079.2010.511171.

Tsai, W. C., Chi, N. W., Huang, T. C., \& Hsu, A. J. (2011). The effects of applicant resume contents on recruiters' hiring recommendations: The mediating roles of recruiter fit perceptions. Applied Psychology: An International Review, 60, 231-254. doi:10.1111/j.1464-0597.2010.00434.x

Tucker, J. S., Sinclair, R. R., \& Thomas, J. L. (2005). The multilevel effects of occupational stressors on soldiers' well-being, organizational attachment and readiness. Journal of Occupational Health Psychology, 10(3), 276-299.

United States Department of Labor. (2014). Bureau of Labor Statistics. Retrieved from http://www.bls.gov/news.release/vet.nr0.htm

U.S Department of Veteran Affairs. (2013). What are KSAs? Retrieved from va.gov.

U.S. Equal Employment Opportunity Commission. (2012). About EEOC. Retrieved from http://www.eeoc.gov/eeoc/index.cfm

van Bogaert, D. (2008). Employees returning from military leave: Newest potential legal liability for employers. Employee Relations Law Journal, 33, 61-69. Retrieved from http://www.aspenpublishers.com/Product.asp?catalog_name=Aspen\&product_id=990003600 0

Van de Ven, A. H., \& Sun, K. (2011). Breakdowns in implementing models of organization change. Academy of Management Perspectives, 25, 58-74. doi:10.5465/AMP.2011.63886530

Walker, J. A. (2008). Employment characteristics of gulf war-era II veterans in 2006: A visual essay. Monthly Labor Review, 131, 3-13. Retrieved from http://www.bls.gov/mlr/

Whelan-Berry, K. S., \& Somerville, K. A. (2010). Linking change drivers and the organizational change process: A review and synthesis. Journal of Change Management, 10, 175-193. doi:10.1080/14697011003795651

The White House, Office of the Press Secretary. (2011). President Obama's commitment to employing America's veterans [Press release]. Retrieved from http://www.whitehouse.gov/the-press-office/2011/08/05/fact-sheet-president-obama-s-commi 


\section{Macrothink}

tment-employing-america-s-veterans

William, E. N., \& Morrow, S. L. (2009). Achieving trustworthiness in qualitative research: A pan-paradigmatic perspective. Psychotherapy Research, 19, 576-582. doi:10.1080/10503300802702113

Whyman, M., Lemmon, M., \& Teachman, J. (2011). Non-combat military service in the United States and its effects on depressive symptoms among men. Social Science Research, 40, 695-703. doi:10.1016/j.ssresearch.2010.12.007.

Yin, R. K. (2011). Applications of case study research (3rd ed.). Thousand Oaks, CA: Sage Publications.

\section{Copyright Disclaimer}

Copyright for this article is retained by the author(s), with first publication rights granted to the journal.

This is an open-access article distributed under the terms and conditions of the Creative Commons Attribution license (http://creativecommons.org/licenses/by/3.0/). 